\title{
Plasmid DNA recovery from fermentation broths by a combined process of micro- and ultrafiltration: Modeling and application
}

\author{
José C. Nunes ${ }^{\mathrm{a}}$, António M. Morão ${ }^{\mathrm{a}, *}$, Catherine Nunes ${ }^{\mathrm{a}}$, Maria Teresa Pessoa de Amorim ${ }^{\mathrm{b}}$, \\ Isabel C. Escobar ${ }^{\mathrm{c}}$, João A. Queiroz ${ }^{\mathrm{a}}$ \\ ${ }^{a}$ Centro de Investigação em Ciências da Saúde, University of Beira Interior, 6201-001 Covilhã, Portugal \\ ${ }^{\mathrm{b}}$ Department of Textile Engineering, University of Minho, 4800-058 Guimarães, Portugal \\ ${ }^{\mathrm{c}}$ Department of Chemical and Environmental Engineering, University of Toledo, Toledo, $\mathrm{OH} 43606$, USA
}

\section{A R T I C L E I N F O}

Article history:

Received 3 February 2012

Received in revised form

18 April 2012

Accepted 19 April 2012

Available online 22 May 2012

Keywords:

Plasmid DNA recovery

Microfiltration

Ultrafiltration

Modeling

RNA

Genomic DNA

\begin{abstract}
A B S T R A C T
Microfiltration and ultrafiltration operations were used in tandem to isolate and purify a $6050 \mathrm{bp}$ plasmid DNA (pDNA). To achieve primary isolation of the plasmid from fermentation broths, immediately after cell lysis, a $0.2 \mu \mathrm{m}$ microfiltration membrane was selected for solid/liquid separation, which was performed in a diafiltration mode, as an alternative to centrifugation. Then to attain plasmid concentration and purification, an ultrafiltration membrane with a pore radius of $4.1 \mathrm{~nm}$ was selected. Permeation of pDNA and RNA in the two membrane steps was modeled using recently published mass transfer models applicable to the permeation of closed segmented chains and freely-jointed chains, respectively. The permeation of proteins and genomic DNA (gDNA) was also studied in these operations.

The microfiltration operation allowed high plasmid and RNA permeation, as expected. It was observed that significant amounts of gDNA, previously precipitated during the cell lysis step, reappear in solution during the diafiltration step. The effect of the ionic strength on this apparent re-solubilization was investigated, by testing the addition of two different salts to the diafiltration buffer: $\mathrm{CH}_{3} \mathrm{COOK}$ and $\mathrm{CaCl}_{2}$. The results show that these salts can be used to control gDNA apparent re-solubilization. During the ultrafiltration operation high plasmid retention with low adsorption was obtained under low ionic strength conditions. The results also show that a significant removal proteins and the re-solubilized gDNA is achieved, as well as some purification in respect to low molecular weight RNA, since all these components permeate through the ultrafiltration membrane.
\end{abstract}

(c) 2012 Elsevier B.V. All rights reserved.

\section{Introduction}

Since the last decade numerous studies have been published on the possible application of plasmid DNA on gene therapy and to produce DNA vaccines. Regarding gene therapy, naked/plasmid DNA accounted for $18.7 \%$ of all the clinical trials made in 2011 so far, just behind adenovirus (24.2\%) and retrovirus (20.7\%) [1]. Comparing these figures to similarly obtained values by the year 2007 [2] and year 2000 [3], one can see a significant increase in the number of studies performed with this kind of non-viral vectors. For DNA vaccination, many preclinical and clinical trials have also shown a great potential for application [4-7].

To produce plasmid DNA on a large scale, it is necessary to develop highly efficient processes in terms of yield and essentially free of harmful chemicals, like cesium chloride or ethidium

\footnotetext{
* Corresponding author. Tel.: +351 275322304.

E-mail address: ammorao@ubi.pt (A.M. Morão).
}

bromide, solvents as isopropanol, phenol or chloroform; enzymes (like RNase A, proteinase K or lysozyme), that are often used in laboratory techniques should be also avoided [8-14]. Plasmid DNA (pDNA) is usually produced by Escherichia coli cultivation. The first step of downstream processing is cell lysis. Despite some other available techniques, such as mechanical [15] and thermal methods [16,17], alkaline lysis, first described by Birboim and Doly [18], is the most widely used. Alkaline lysis not only disrupts the cell wall, releasing plasmid molecules, but also removes considerable amounts of cell debris, genomic DNA (gDNA) and proteins, which precipitate upon neutralization, leaving RNA as the major contaminant, together with low quantities of gDNA, proteins and endotoxins $[10,19,20]$. Alkaline lysis takes advantage of the renaturation cycle of pDNA molecules [21]. Upon neutralization of the lysate with a high-salt solution, a large quantity of precipitates is formed. For each gram (wet weight) of cells, $2.4 \mathrm{~g}$ of precipitates are typically formed, which in conventional alkaline lysis techniques lead to a concentration of solids of approximately $100 \mathrm{~g} / \mathrm{l}$ [20]. This solid material is highly "gelatinous" in 
nature and tends to flocculate. Any solid-liquid operation can be used, in principle, to remove it from the lysate. Of various laboratory techniques, centrifugation is the operation of choice. However, at larger scales of operation, filtration is preferred $[8,20,22,23]$. Theodossiou et al. [20] studied several filters, with different materials and pore sizes and also the possible application of filter aids. Even the smallest pore size filter $(5 \mu \mathrm{m})$ was unable to fully retain the solid material. Some shear induced degradation of gDNA molecules was also observed. With the addition of filter aids, complete separation was achieved, but at the expense of a reduced capacity and lower yield (due, in part, to plasmid adsorption on the filter aid itself). Moreover, filter aids can create problems as the scale of operation increases, due to the large quantity of solid waste formed and its disposal. Using microfiltration no filter aids are necessary and very high yields can be expected if low plasmid adsorption on the membranes is achieved. Kendall et al. [24] studied the application of a $0.45 \mu \mathrm{m}$ nitrocellulose membrane to purify plasmids from clarified cell lysates; the clarification was carried out by gravity-driven filtration. The use of a highly hydrophobic material such as nitrocellulose enabled a considerable removal of the main hydrophobic contaminants namely RNA, gDNA and some proteins, however it caused significant membrane fouling.

In the present work, the use of a two-step membrane filtration process was studied, using hydrophilic membranes to avoid as much as possible adsorption phenomena and fouling; a microfiltration membrane was used to perform a diafiltration of the lysates and an ultrafiltration membrane to concentrate and further purificate the plasmid. The study included modeling the permeation of the plasmid in the two membrane steps, using a recently published theoretical model [25]. A model for permeation of flexible linear polymers adapted from [26] to include, like in the case of the plasmid, electric charge effects on mass transfer, is used here for the first time to predict the sieving coefficients of the main different types of RNA present in the lysates, and also to interpret experimental results of gDNA removal in the ultrafiltration operation. The study of the effect of the ionic strength on the permeation of pDNA, gDNA, RNA and proteins, in the two membrane steps was also carried out, as well as the effect of $\mathrm{CaCl}_{2}$ addition to the lysates before filtration. This salt is capable of precipitating most of the RNA present [11].

\section{Materials and methods}

\subsection{Plasmid production and cell lysis}

Cellular growth of E. coli DH5 $\alpha$, containing a $6050 \mathrm{bp}$ plasmid, pVAX1-lacZ, was carried out as described in [12]. Then, to $4 \mathrm{ml}$ of a $120 \mathrm{~g} / \mathrm{l}$ (wet weight) cell suspension in $\mathrm{T}_{50} \mathrm{E}_{10}$ buffer $(50 \mathrm{mM}$ Tris (Fisher BioReagents) and $10 \mathrm{mM}$ EDTA (Sigma), at $\mathrm{pH}=8.0$ ), $4 \mathrm{ml}$ of a solution containing $0.2 \mathrm{M} \mathrm{NaOH}$ (Panreac) and 1\% SDS (Himedia) were added to produce cell lysis. The mixture was kept at room temperature for $5 \mathrm{~min}$, and then $4 \mathrm{ml}$ of $3 \mathrm{M}$ potassium acetate (Sigma-Aldrich ReagentPlus) at $\mathrm{pH} 5.0$ solution, with the $\mathrm{pH}$ adjusted with acetic acid (Panreac), were added to it. A large quantity of suspended solids was then obtained, and the suspension was kept in ice for $15 \mathrm{~min}$. The method described here is, therefore, adapted from the method originally developed by Birnboim and Doly [18].

\subsection{Membrane filtration tests}

All the membrane filtration experiments were performed in a $10 \mathrm{ml}$ stirred cell from Amicon/Millipore, model 8010. A hydrophilic nylon microfiltration membrane, with a nominal pore diameter of $0.2 \mu \mathrm{m}$, Nylaflo from Pall Corporation, USA was used.
In each test, a new membrane disc was placed in the cell, being initially flushed with MiliQ water to ensure the complete removal of all traces of membrane preservatives. Then, water was removed and $10 \mathrm{ml}$ of lysate were introduced in the filtration cell. A continuous diafiltration of the lysates was performed in all the experiments until a dilution factor near 3 was reached. In the case of total permeation of the plasmid through the membrane (i.e., $S_{o b s}=1$ ) this would ensure a pDNA recovery of about $95 \%$. These experiments were performed under conditions of constant permeate flow of $0.5 \mathrm{ml} / \mathrm{min}$, imposed by a peristaltic pump Watson-Marlow model $403 \mathrm{U}$, placed after the membrane (thus working by suction). This pump had 10 rotating elements that ensure an almost non-pulsed flow. The effective membrane area for this cell model is $4.1 \times 10^{-4} \mathrm{~m}^{2}$. The stirring speed was kept in all the experiments at $760 \mathrm{~min}^{-1}$ (previous calibration of the system was performed). Three different buffer solutions were tested for diafiltration: (A) $10 \mathrm{mM}$ Tris- $\mathrm{Cl}$ at $\mathrm{pH}=8.0$; (B) $1 \mathrm{M}$ $\mathrm{CH}_{3} \mathrm{COOK}$ at $\mathrm{pH}=8.0$ and $(\mathrm{C}) 1 \mathrm{M} \mathrm{CaCl}_{2}$ (Sigma-Aldrich) in $10 \mathrm{mM}$ Tris $-\mathrm{Cl}$ at $\mathrm{pH}=8.0$. The permeates obtained in the first membrane filtration step were subjected to a second filtration operation, using a fluoro polymer membrane of $100 \mathrm{kDa}$ cut-off, FS4OPP from DSS/Alfa-Laval. A similar stirred cell was used for ultrafiltration as for microfiltration. Due to the lower hydraulic permeability of the ultrafiltration membrane, tests were carried out by applying constant pressure ( 1 bar, with compressed $\mathrm{N}_{2}$ ) rather than at constant flux.

\subsection{Analytical}

\subsubsection{Plasmid DNA assay}

Plasmid concentration was measured by hydrophobic interaction chromatography (HIC) using a technique adapted from Diogo et al. $[12,27,28]$. A HIC Source 15 PHE PE column from Amersham Biosciences (GE Healthcare) was connected to a Waters HPLC system (Waters, Milford, MA, USA). The column was initially equilibrated with $1.5 \mathrm{M}\left(\mathrm{NH}_{4}\right)_{2} \mathrm{SO}_{4}$ (Pronalab) in $10 \mathrm{mM}$ Tris/HCl ( $\mathrm{pH}$ 8.0) buffer (Tris buffer). Samples of $20 \mu \mathrm{l}$ were injected and eluted at a constant flow rate of $1 \mathrm{ml} / \mathrm{min}$. After $2 \mathrm{~min}$ from injection, the eluent was instantly changed to $10 \mathrm{mM}$ Tris/ $\mathrm{HCl}$ buffer $(\mathrm{pH} \mathrm{8.0)}$ in order to elute bounded species. This concentration was maintained for $5 \mathrm{~min}$ before re-equilibration of the column in order to prepare it for the next run. The absorbance of the eluate was recorded at $260 \mathrm{~nm}$. The concentration of pDNA in each sample was calculated from a calibration curve; the pDNA standards were obtained using a commercial purification kit from Qiagen, Hilden, Germany.

\subsubsection{Protein assay}

Total protein concentration in the samples was measured using a Pierce micro-BCA assay (Thermo Scientific, Rockford, IL, USA) similarly as described in [12]. Briefly, $50 \mu \mathrm{l}$ of sample was mixed with $200 \mu \mathrm{l}$ of BCA reagent in a microplate and then incubated for $30 \mathrm{~min}$ at $60{ }^{\circ} \mathrm{C}$. The plate was cooled to room temperature for another $15 \mathrm{~min}$ and then the absorbance was measured at $595 \mathrm{~nm}$ in a microplate reader. Calibration curves were prepared with BSA standards in the range $25-500 \mu \mathrm{g} / \mathrm{ml}$. To avoid salt interferences with the method, the samples were previously desalted by size exclusion chromatography in PD-10 columns from Amersham Biosciences (GE Healthcare), according to the manufacturer's instructions, using $\mathrm{NaCl}$ (Panreac) $0.15 \mathrm{M}$ in $10 \mathrm{mM}$ Tris ( $\mathrm{pH}$ 8.0) buffer as eluent.

\subsubsection{Genomic DNA assay}

In order to measure gDNA concentrations in the samples, a real time-PCR method adapted from [29] was used. Sense (5'-ACACGGTCCAGAACT-CCTACG-3') and antisense (5'-GCCGGTGCTTCTTCTGCGGGTAACGTCA-3') primers were used to amplify 
a $181 \mathrm{bp}$ fragment of the $16 \mathrm{~S}$ rRNA gene of E. coli. Samples of $1 \mu \mathrm{l}$ were mixed with $19 \mu \mathrm{l}$ SYBR Green/ROX qPCR Master Mix $(2 \times)$ from Fermentas International. Amplification was carried out in a Bio-Rad IQ5 thermocycler and monitored by the change in fluorescence of the DNA-binding dye. A standard curve was obtained by consecutive dilution of a $E$. coli DH5 $\alpha$ gDNA standard; this was isolated with a Wizard gDNA purification kit from Promega, Madison, WI, USA. Correlation coefficients higher than 0.90 were generally obtained.

Table 1

Main nucleic acids present in the lysates and relevant properties for modeling purposes.

\begin{tabular}{lllll}
\hline Compound & $s \times 10^{13}(\mathrm{~s})$ & $M w(\mathrm{Da})$ & $r_{s} \times 10^{9}(\mathrm{~m})$ & $D \times 10^{11}\left(\mathrm{~m}^{2} \mathrm{~s}^{-1}\right)$ \\
\hline 5S RNA & 5 & 40800 & 3.39 & 7.29 \\
16S RNA & 16 & 523940 & 13.6 & 1.82 \\
23S RNA & 23 & 987360 & 17.8 & 1.39 \\
pVAX-LacZ1 & - & $3.99 \mathrm{E}+06$ & 83.2 & 0.297 \\
\hline
\end{tabular}

\subsubsection{Agarose gel electrophoresis}

Samples were analyzed by horizontal electrophoresis using $1.0 \%$ agarose gels prepared in TAE buffer $(40 \mathrm{mM}$ Tris, $20 \mathrm{mM}$ acetic acid and $1 \mathrm{mM}$ EDTA, pH 8.0) in the presence of $0.5 \mu \mathrm{g} / \mathrm{ml}$ of ethidium bromide (Amresco $10 \mathrm{mg} / \mathrm{ml}$ stock solution). Electrophoresis was carried out at $110 \mathrm{~V}$ during $40 \mathrm{~min}$, in TAE buffer, in a Bio-Rad's cell. The gels were visualized in an Essential V2 transilluminater from Uvitec. To avoid salt interferences with the method, some samples were desalted, by isopropanol (Fisher Chemical) precipitation, prior to the analysis. Briefly, 1 volume isopropanol, at room temperature, was added and mixed with the sample. The mixture was then centrifuged at $16,000 \mathrm{~g}$ for $15 \mathrm{~min}$ at $4{ }^{\circ} \mathrm{C}$. After discarding the supernatant, the pellet was dissolved in the appropriate volume of Tris buffer.

\subsubsection{Size exclusion chromatography}

Alkaline lysates were analyzed by size exclusion chromatography (SEC) in Sephacryl S-100 h from GE Healthcare. The gel, $48 \mathrm{ml}$, was packed in a column with $1.5 \mathrm{~cm}$ of internal diameter, connected to an Äkta purifier FPLC system (GE Healthcare). The a

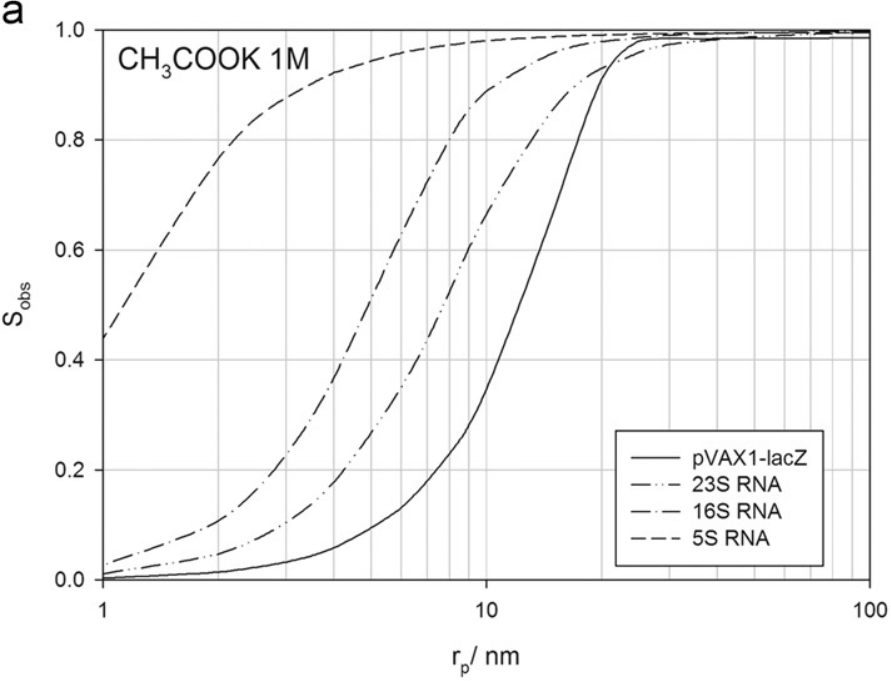

C

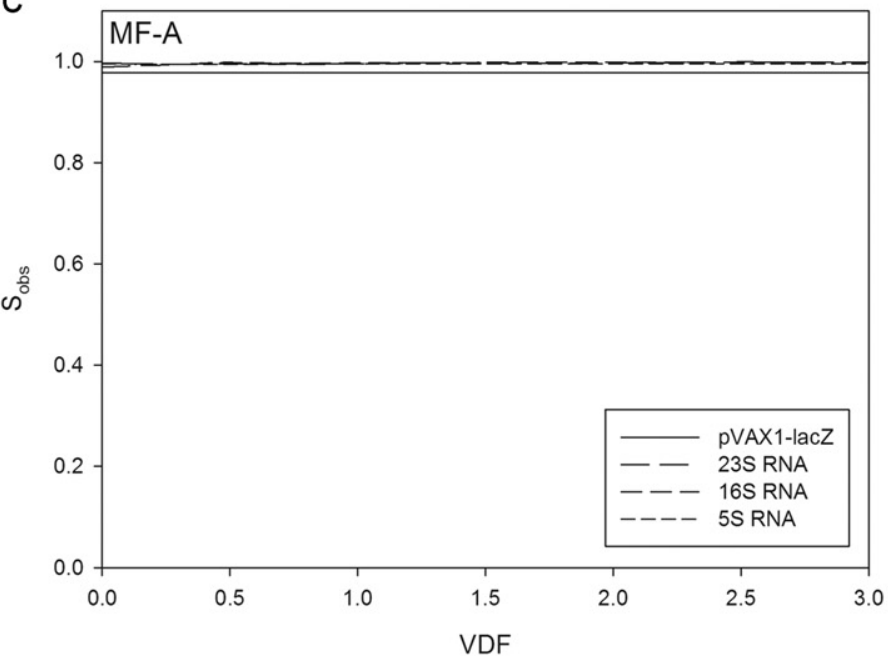

b

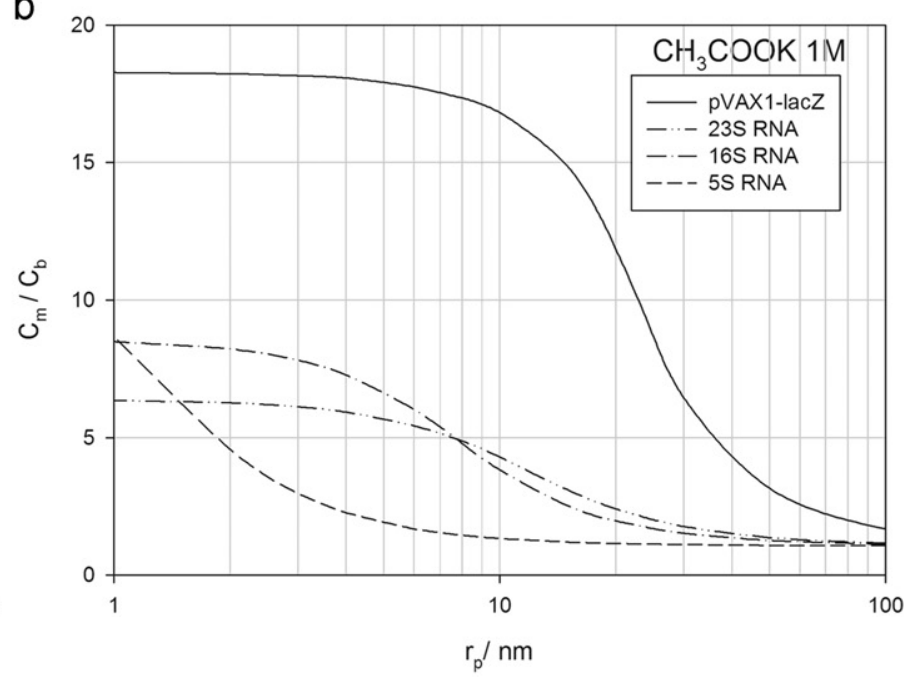

d

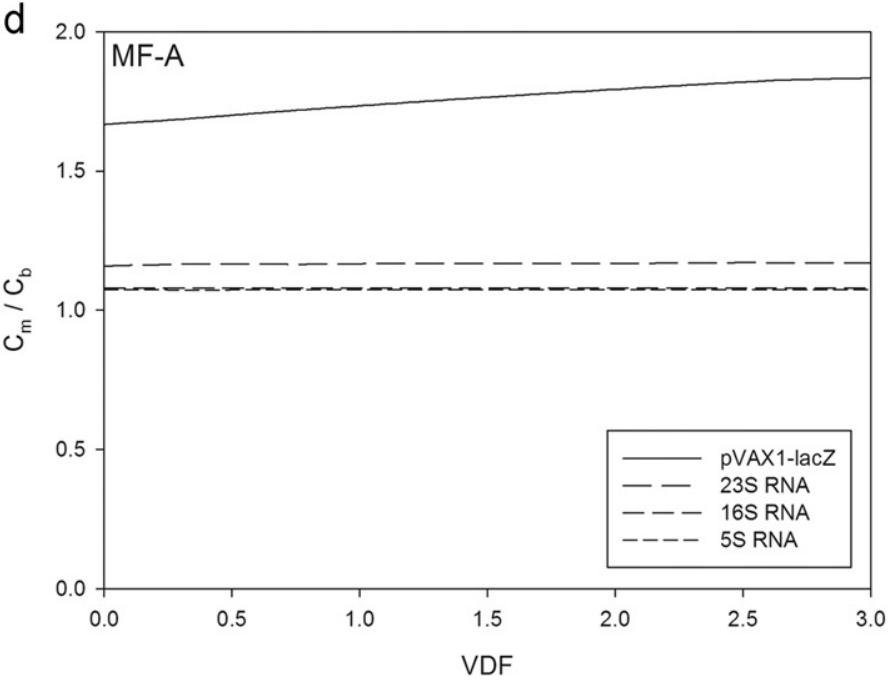

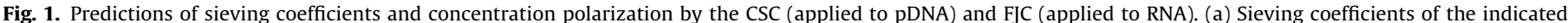

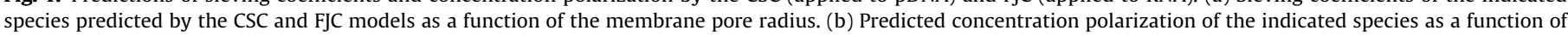

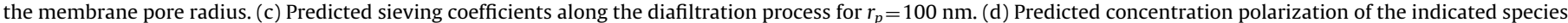
along the diafiltration process for $r_{p}=100 \mathrm{~nm}$. Conditions: $J_{v}=20 \times 10^{-6} \mathrm{~m} \mathrm{~s}^{-1}(0.5 \mathrm{ml} / \mathrm{min}), \omega=760 \mathrm{~min}^{-1}, T=25^{\circ} \mathrm{C}$. 
eluent was $\mathrm{NaCl} 150 \mathrm{mM}$ in $10 \mathrm{mM}$ Tris buffer at $\mathrm{pH}$ 8.0. Lysate samples of $1 \mathrm{ml}$ were injected and the eluent flow was $0.5 \mathrm{ml} / \mathrm{min}$. The absorbance was continuously monitored at $260 \mathrm{~nm}$.

\subsection{Simulations}

A recently published model on pDNA permeation through narrow pores [25] was used to estimate sieving coefficients, Sobs, of pDNA in the membranes tested under the approach that essentially all the pDNA exists in its supercoiled isoform. Under this approach pDNA is simulated as a closed segmented chain (CSC), with its radius of gyration, $r_{g}$, being estimated for a certain ionic strength, using Eq. (7) of [25]. With the $r_{g}$ value and the membrane pore radius, $r_{p}$, one can estimate the value of the intrinsic sieving coefficient of the plasmid, $S_{m}$, using Eq. (1) of [25]. Since plasmids are highly-charged molecules, the salts present strongly affect their concentration polarization, thereby affecting the values of $S_{o b s}$. This effect can be considered in the calculations by using the extended Nernst-Planck (NP) equation to describe the mass transfer of each ionic component of the system in the concentration polarization layer [25]. The minimum number of components required for simulating the effect of the salts present on plasmid permeation is 3: the plasmid (component 1 ) a co-ion of the plasmid (component 2) and a counter-ion (component 3). The concentrations of components 2 and 3 are adjusted to obtain the desired ionic strength, and at the same time electroneutrality. This method is carefully explained in [25]. More ionic components can be introduced in the system, however, this considerably increases the complexity of the numeric calculations. Apart from this, no methods are available for estimating $r_{g}$ of plasmids in the case of mixed electrolytes. Accordingly, for simulating diafiltration of the lysates with buffers "A" and " $B$ ", components 2 and 3 were considered to be $\mathrm{CH}_{3} \mathrm{COO}^{-}$ and $\mathrm{K}^{+}$respectively, with initial concentrations of $1 \mathrm{M}$, since these are, by far, the main salts present in the lysates. In the case of $\mathrm{CaCl}_{2}$ diafiltration with buffer " $\mathrm{C}$ " component 2 was $\mathrm{Cl}^{-}$and component 3 was $\mathrm{Ca}^{2+}$, with initial concentrations of $2 \mathrm{M}$ and $1 \mathrm{M}$ (as $\mathrm{CaCl}_{2}$ is previously added to the lysates before diafiltration). Since $\mathrm{K}^{+}$and $\mathrm{CH}_{3} \mathrm{COO}^{-}$ions are also present in significantly high concentrations in the lysates, besides $\mathrm{CaCl}_{2}$ the effect of the salts present is underestimated in this case. As will be seen later, this does not significantly affect the obtained results from the simulations since the ionic strength is already very high ( $3 \mathrm{M})$ by considering $\mathrm{Ca}^{2+}$ and $\mathrm{Cl}^{-}$only, as the main ions present.

Since RNA is one of the major contaminants in solution $[11,30]$, it is also of great interest to predict for these molecules their sieving coefficients in the membrane operations studied. The three main types of $E$. coli ribosomal RNA, constitute most of the total RNA that are present in the lysates, more specifically $23 \mathrm{~S}$ RNA (2904 nucleotides; $\left.9.87 \times 10^{5} \mathrm{Da}\right)$, 16S RNA (1541 nucleotides; $\left.5.24 \times 10^{5} \mathrm{Da}\right)$ and $5 \mathrm{~S}$ RNA (120 nucleotides; $\left.4.08 \times 10^{4} \mathrm{Da}\right)$. The first two constitute the main part of what can be called high molecular weight RNA (HMw RNA) and the latter is the main component of what can be called low molecular weight RNA (LMw RNA) to designate the two main fractions containing RNA that can be seen in electrophoretograms of the lysates. From the sedimentation coefficients of these species their hydrodynamic radii can be estimated using the following relationship, derived from basic theory on ultracentrifugation [31]:

$r_{s}=\left(\frac{1}{6 \pi \eta}\right)\left(\frac{M W}{N_{A}} \frac{\left(1-v_{s} \rho\right)}{s}\right)$

The estimated values of $r_{s}$ for the different types of RNA found in the lysates are indicated in Table 1, where these can be compared with the $r_{s}$ value estimated for the plasmid studied in this work. Contrary to pDNA molecules that are double stranded and circular, RNA molecules are single stranded and linear. Although their bases have tendency to bind, the freely jointed chain model (FJC) is a possible way of representing their structure, which is tested here. Under this approach, these molecules are considered to be linear and highly flexible, a property that should explain their ability of permeating through pores of considerable smaller size than their hydrodynamic radii, like in the case of pDNA. Using the FJC model

\section{Table 2}

Total protein and genomic DNA (gDNA) in the permeates after diafiltration (microfiltration) with different buffer solutions and their removal $\left(R_{1}\right)$ in the diafiltration operation (tests MF-A, MF-B and MF-C). Initial values found in the lysates: $200 \mu \mathrm{g} / \mathrm{ml}$ of total protein and $13.4 \mu \mathrm{g} / \mathrm{ml}$ of gDNA.

\begin{tabular}{lllll}
\hline Test & Proteins $(\mu \mathrm{g} / \mathrm{ml})$ & $R_{1}(\%)$ & $g D N A(\mu \mathrm{g} / \mathrm{ml})$ & $R_{1}(\%)$ \\
\hline MF-A & 61 & 7.7 & 43.0 & -865 \\
MF-B & 71 & -6.3 & 18.1 & -306 \\
MF-C & $172^{\mathrm{a}} / 45$ & $14^{\mathrm{a}} / 33$ & $2.4^{\mathrm{a}} / 5.5$ & $71^{\mathrm{a}} /-44$ \\
\hline
\end{tabular}

a Just after precipitation with $\mathrm{CaCl}_{2}$. a

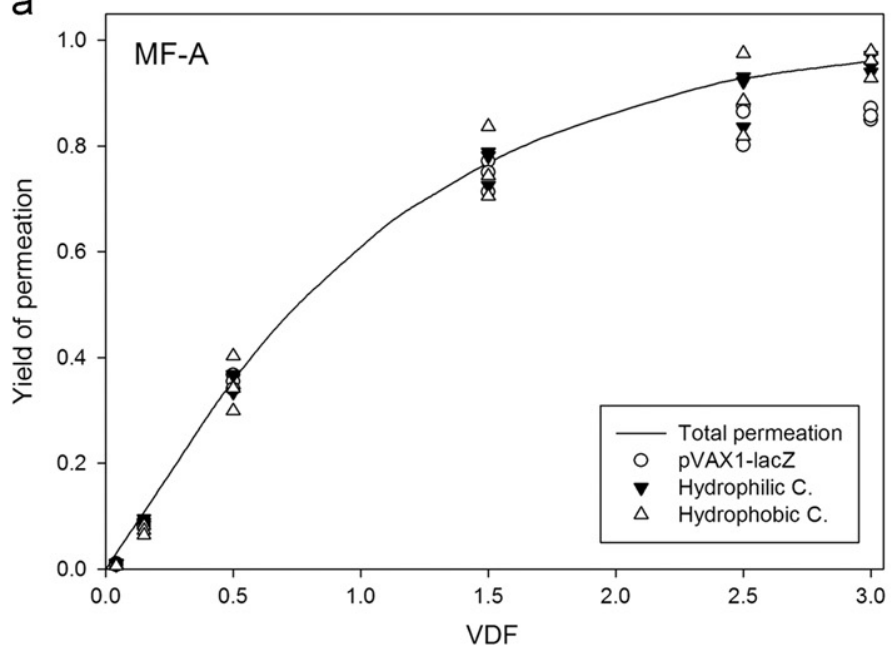

b

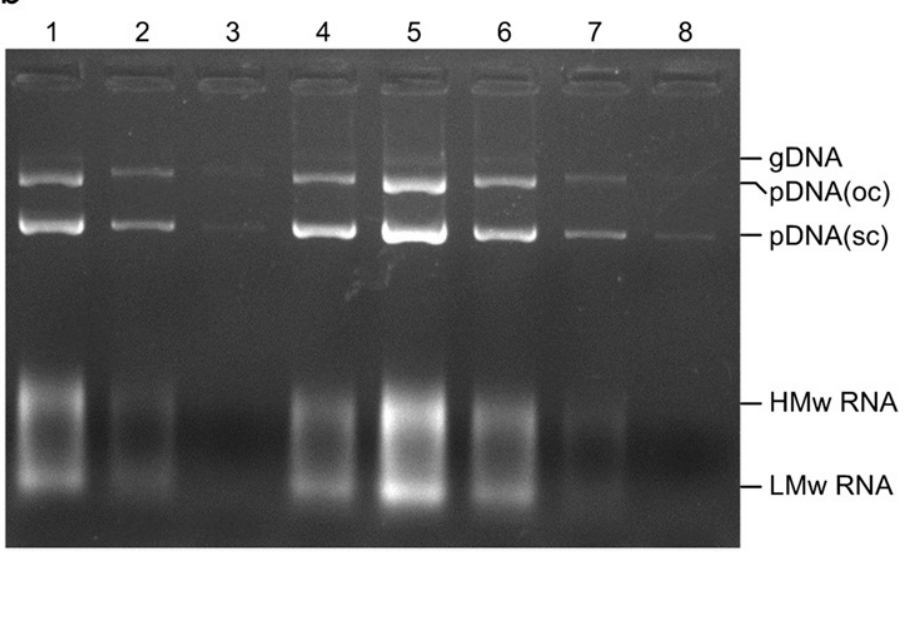

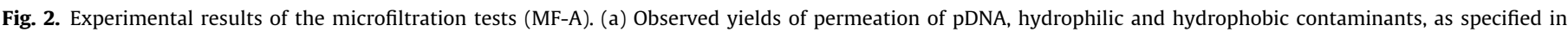

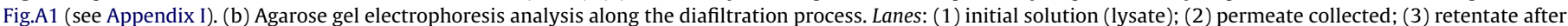
diafiltration; (4-8) permeate samples for $\mathrm{VDF}=0.04,0.15,0.5,1.5,2.5$, respectively. (oc) indicates open circular; (sc) indicates supercoiled. 
approach, the radius of gyration of the different types of RNA can be approximately estimated as 1.5 times the value of $r_{s}$ [26]. With the $r_{g}$ values and the average pore radii of the membranes studied in this work $S_{m}$ values can be estimated using Eq. (1) of [25]. Since

a

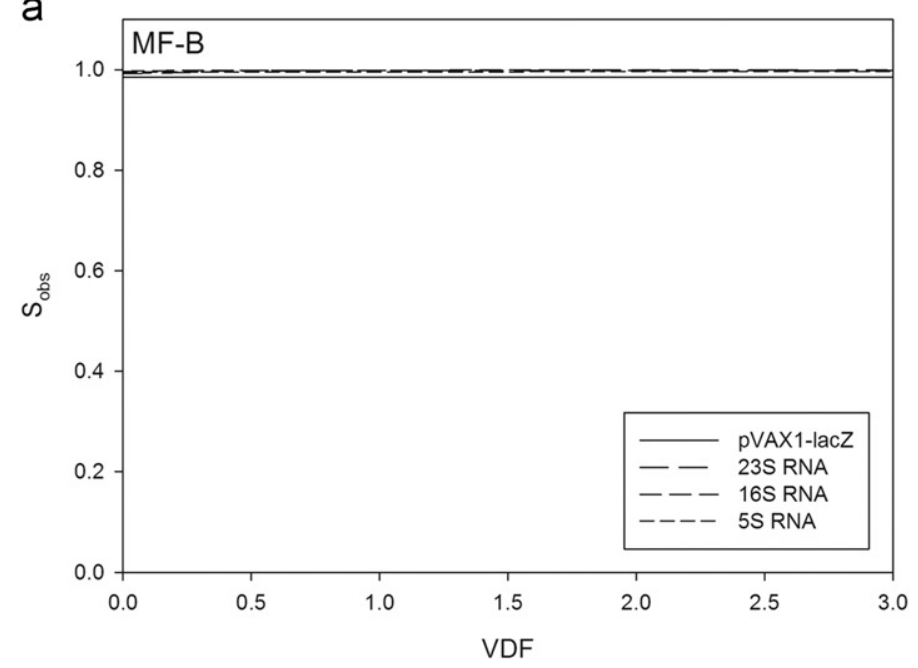

C

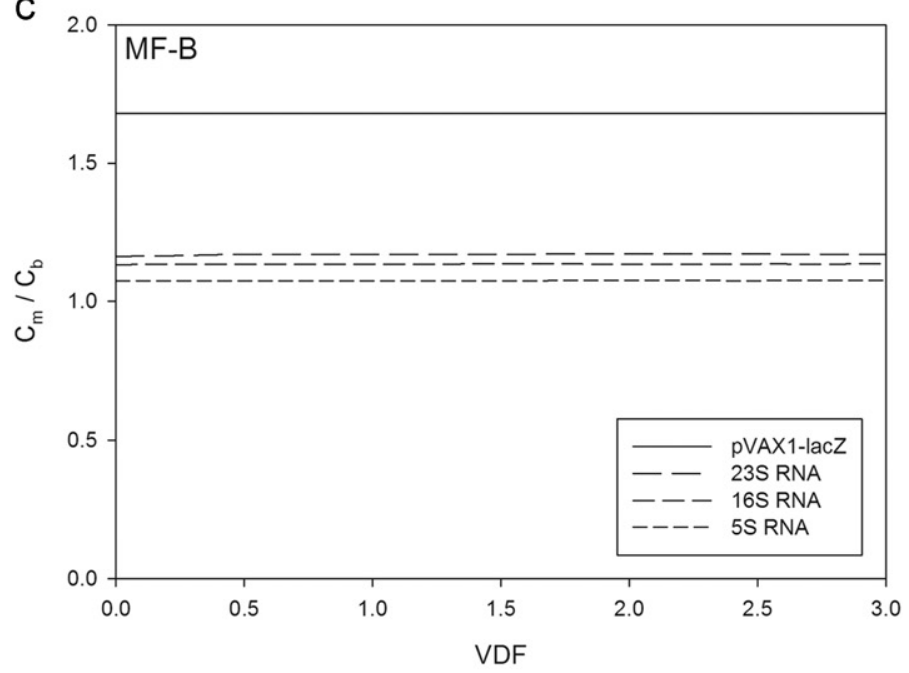

e

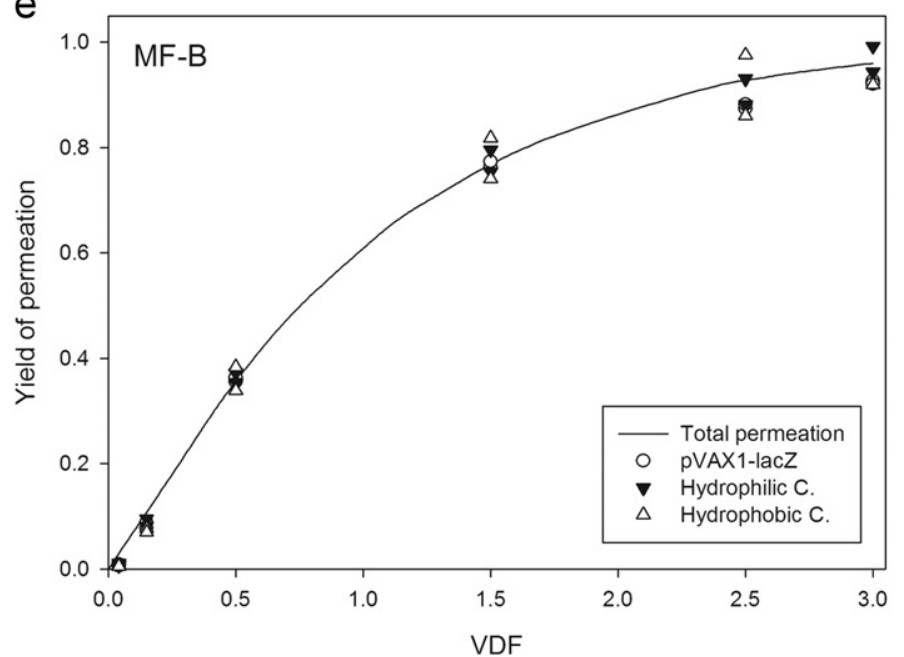

RNA molecules are highly charged, their concentration polarization is also very dependent on the salts present in solution; therefore, a numerical method similar to that used for predicting pDNA sieving coefficients was used for estimating $S_{o b s}$ of the RNA molecules.

b

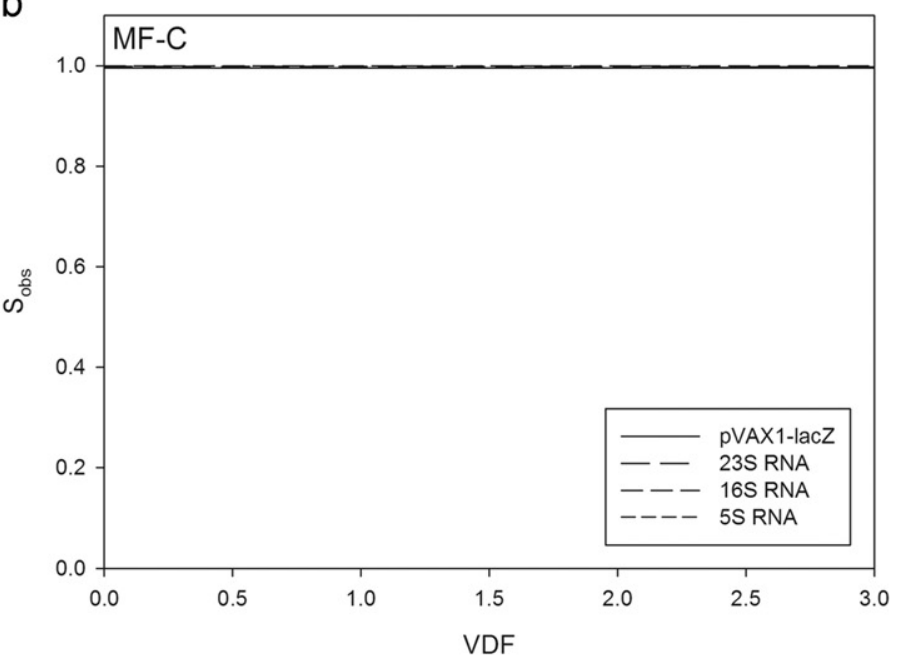

d

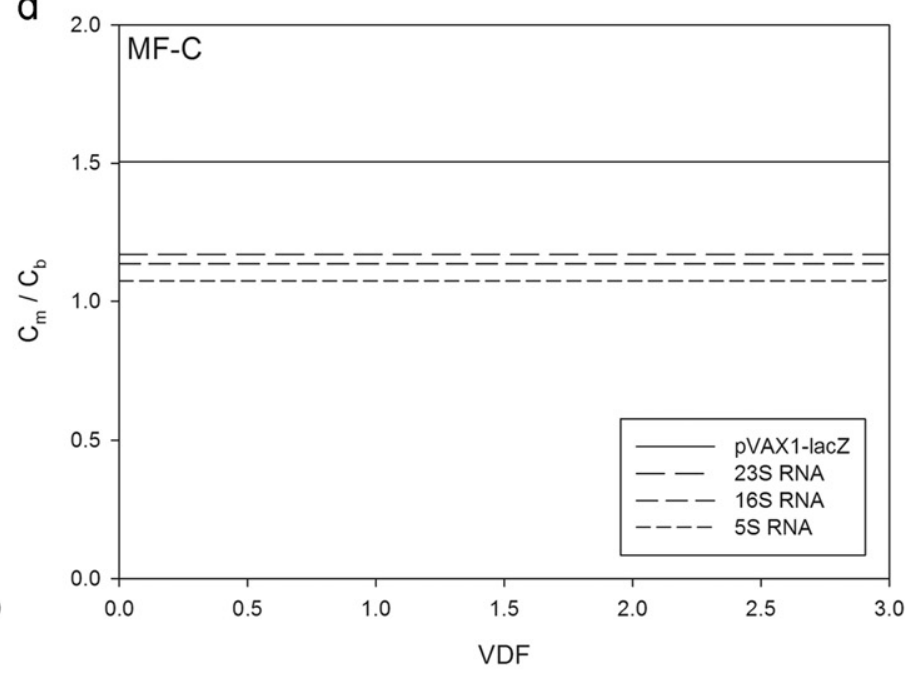

f

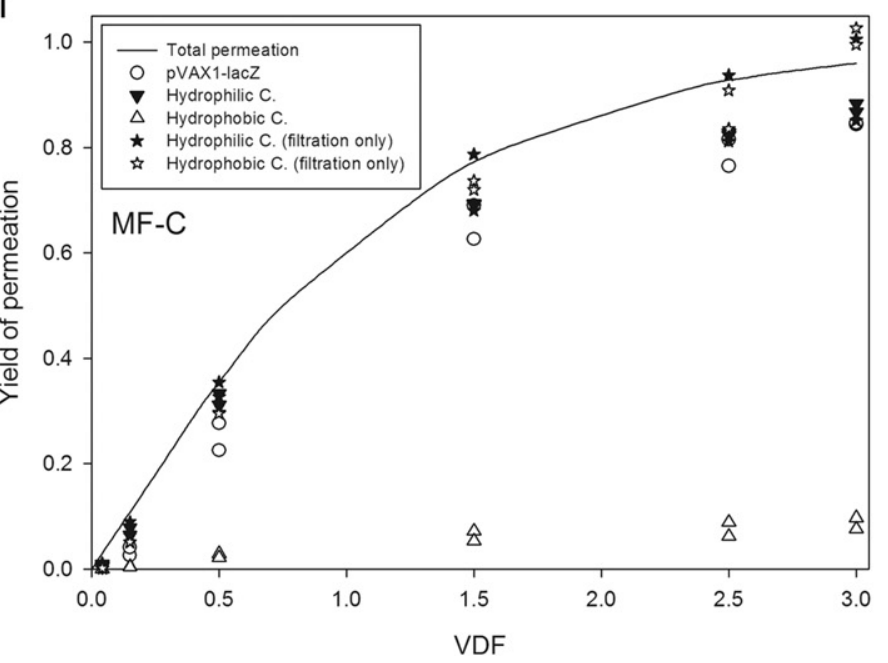

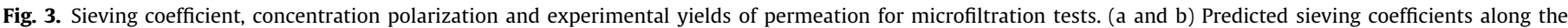

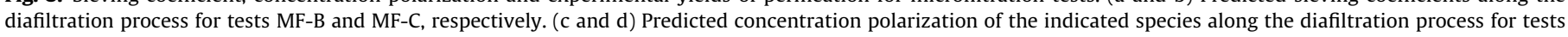

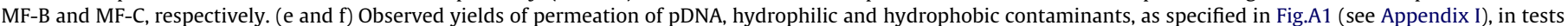
MF-B and MF-C, respectively. The simulations were performed for the operating conditions indicated in Fig.1. 


\section{Results and discussion}

\subsection{Microfitration studies}

Three microfiltration tests were conducted using diafiltration buffer A (MF-A), buffer B (MF-B) and buffer C (MF-C), respectively (as specified in Section 2.2) Previous simulation of the microfiltration process was performed to select the correct pore size.

\subsubsection{Simulations}

The predictions of the CSC and FJC models regarding permeation of pDNA and the main different types of RNA present in lysates as a function of the membrane pore radius, considering $1 \mathrm{M}$ of $\mathrm{CH}_{3} \mathrm{COOK}$ as the initial concentration of salts are shown in Fig. 1. Typical operating conditions used with Amicon 8010 stirred cells were selected to perform the simulations, more specifically a moderate permeate flow, $0.5 \mathrm{ml} / \mathrm{min}\left(73 \mathrm{l} / \mathrm{h} \mathrm{m}^{2}\right)$, and a moderate stirring speed, $760 \mathrm{~min}^{-1}$. As it can be seen in Fig. 1(a), a pore radius of at least $30 \mathrm{~nm}$ is required to obtain total permeation of the plasmid under these conditions; however, the use of a higher pore size can considerably decrease plasmid concentration polarization which is known to cause its adsorption on previously studied membranes [25]. As can be seen in Fig. 1(b), as the value of $r_{p}$ approaches $100 \mathrm{~nm}$ the predicted value of $C_{m} / C_{b}$ approaches 1 . Thus, it is concluded that a microfiltration membrane with a pore diameter near $0.2 \mu \mathrm{m}\left(r_{p} \sim 100 \mathrm{~nm}\right)$ should be used. The use of wider pores does not increase plasmid permeation and will enable more intrapore fouling by impurities such as cell debris. No retention of the RNA species considered in the calculations is

a

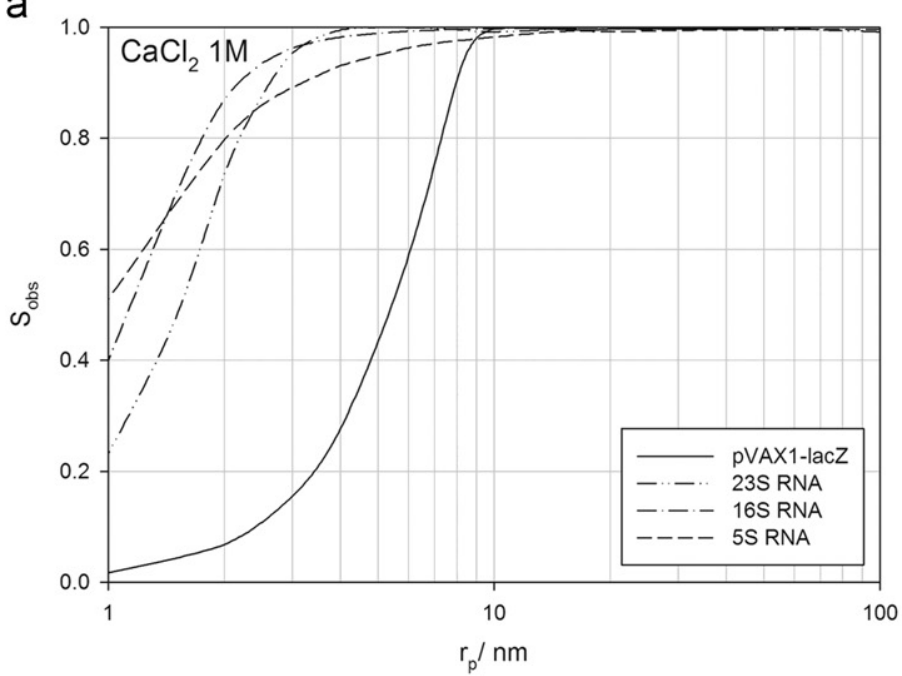

C

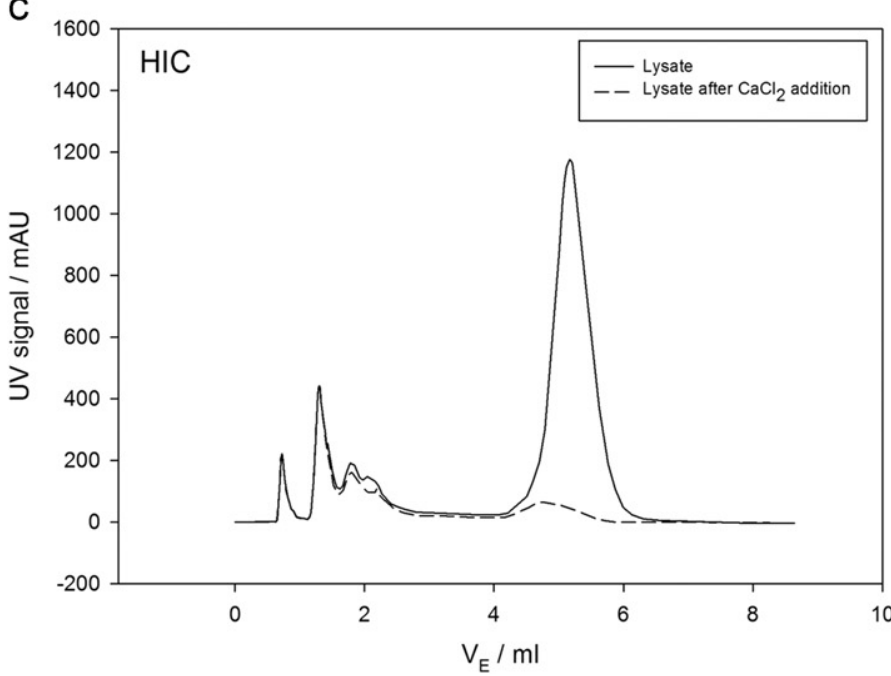

predicted for this pore size, as it can be seen in Fig. 1(a). To achieve separation of RNA from the plasmid considered in this work, the simulations indicate that an ultrafiltration membrane with a pore radius between 2 and $5 \mathrm{~nm}$ should be used (in a second membrane filtration step) to retain the plasmid, allowing the RNA species to permeate according to their molecular dimensions.

For the selected pore size of $100 \mathrm{~nm}$, simulations were carried out for the entire diafiltration process, considering $10 \mathrm{mM}$ Tris- $\mathrm{Cl}$ at $\mathrm{pH}=8.0$ (buffer "A"; see Section 2.2) as the diafiltration buffer. These tests are labeled as MF-A, for the sake of simplicity. The simulations indicate that pDNA and the different RNA species considered should freely permeate through the membrane during the diafiltration process and the concentration polarization should remain nearly constant, as it can be seen in Fig. 1(c) and (d).

\subsubsection{MF-A tests}

Experimental values of plasmid yield of permeation as a function of the volumetric dilution factor, VDF, for MF-A tests are shown in Fig. 2(a) and compared with the corresponding theoretical predictions (which correspond to total permeation). The yield of permeation of a certain species is defined here as the ratio of the amount of that species in the permeate to the amount of that species in the feed solution; considering that the objective of the microfiltration operation is the total permeation of the plasmid, this ratio also corresponds to its recovery yield. All the tests were made in quadruplicate. As it can be seen, pDNA recovery yields obtained for a $\mathrm{VDF}=3.0$ were high, $(86 \pm 1) \%$ in average, but did not reached the theoretical value of $95 \%$ expected. Only $(3.8 \pm 0.1) \%$ of the total pDNA was retained by the membrane and found in the concentrate, therefore suggesting that near $10 \%$ of the plasmid became adsorbed on the membrane.

b

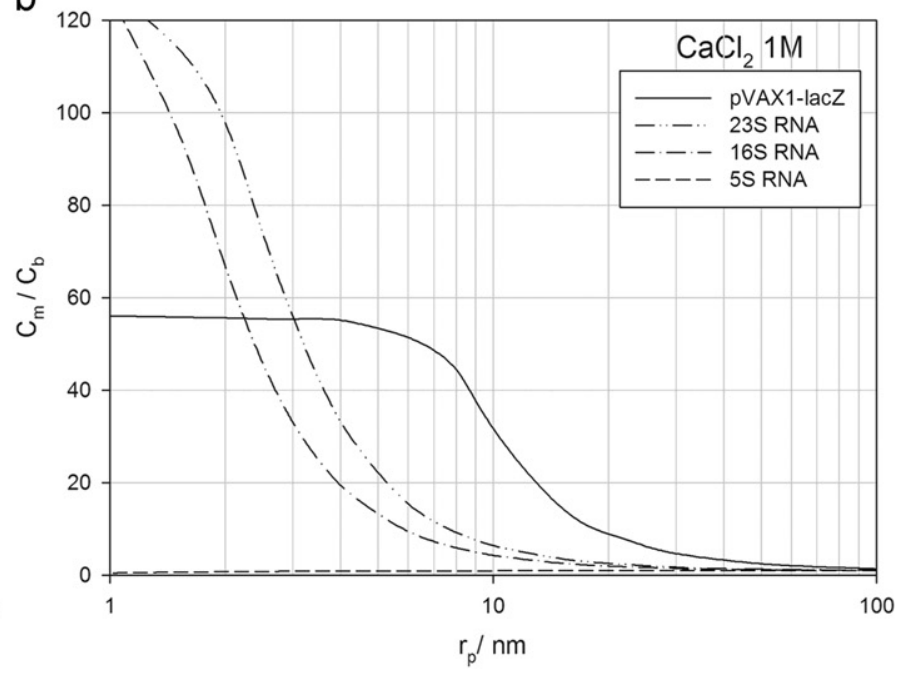

d

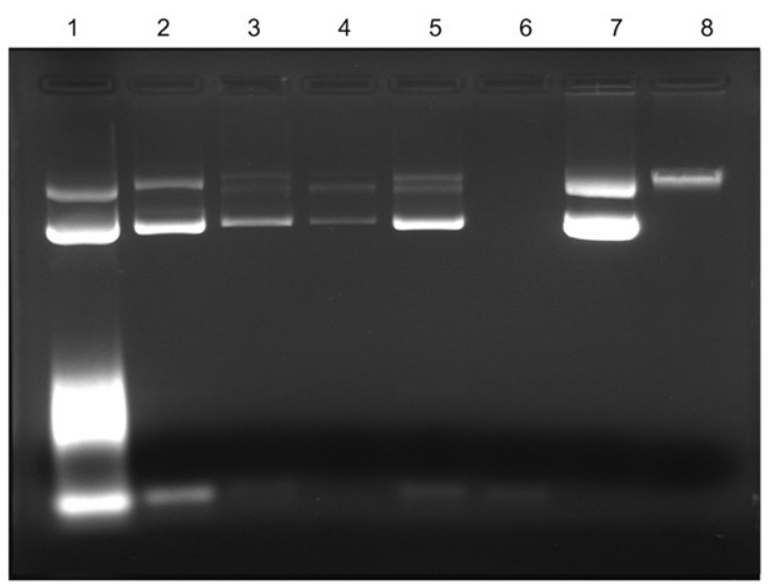

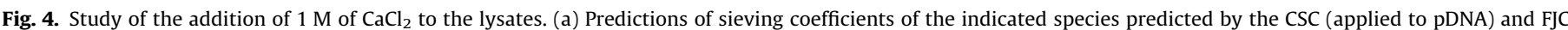

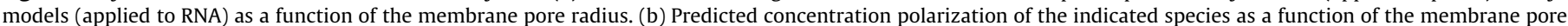

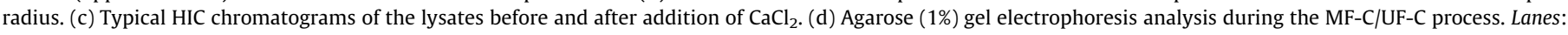

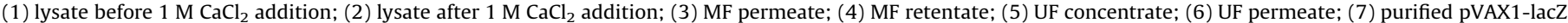
marker; (8) E. coli DH5 $\alpha$ gDNA sample. 
The HIC technique used for pDNA assays (Section 2.3.1) was also used to provide information about the content in soluble contaminants of a certain sample and therefore their removal (see Appendix I). Of particular practical interest is the possibility of relating RNA permeation with the removal of hydrophobic contaminants, since this is a major contaminant. As can be seen in Fig. 2(a) the yield of permeation of hydrophobic contaminants was generally high in the first membrane filtration step, indicating a low removal of the RNA present. The electrophoresis analysis, shown in Fig. 2(b) confirms the idea that the RNA present permeates through the membrane, together with pDNA.

Proteins and gDNA were estimated using the specific methods indicated in Section 2.3. Total protein and gDNA removal data, respectively obtained by the BCA method (see Section 2.3.2) and real time PCR, is shown in Table 2. Low retention of proteins was found in the diafiltration of the lysates (see tests labeled MF-A), in agreement with the low removal of hydrophilic contaminants found by HIC. The results show that there is a tendency of gDNA to return to solution, back from the suspended solids, as the negative removal values indicate. Since the suspended solids need to contact the diafiltration buffer during the filtration process (to achieve high pDNA recovery yields) when optimizing a filtration system for large scale applications this shows that it is essential to have a careful control of the shear acting on the suspended solids in order to decrease as much as possible gDNA mechanical damage and re-solubilization. It is important to note that this issue should not be viewed as a disadvantage of the membrane filtration process when compared to centrifugation; in fact, high shear on the suspended solids is also expected in industrial continuous centrifuges $[8,20,22,23]$.

\subsubsection{MF-B tests}

To avoid the excessive re-solubilization of gDNA, the possibility of keeping the ionic strength approximately constant during the diafiltration process, by using $\mathrm{CH}_{3} \mathrm{COOK} 1 \mathrm{M}$ in Tris at $\mathrm{pH}=8.0$ (buffer "B"; see Section 2.2) was investigated. These tests are labeled MF-B. Theoretically, it was expected that this would not change the sieving coefficients of pDNA (or the RNA species) or their concentration polarization, as shown in Fig. 3(a) and (c), since the pore size is high enough.

Experimentally, the results shown in Fig. 3(e) confirm that the permeation of pDNA and contaminants remained high, with a slight increase in the pDNA recovery yield, which was found to be $(92.4 \pm 0.4) \%$ under these conditions. The retention of pDNA was found to be $(4.4 \pm 0.1) \%$, therefore suggesting a decrease in pDNA adsorption, which leads to a better agreement of the plasmid sieving coefficients with the model predictions. As it can be seen in Table 2, the protein removal remained low, but a significant change was found in the gDNA content of the permeates, which shows a decrease of almost $60 \%$. This result strongly suggests that the re-solubilization of gDNA can be, in fact, decreased by increasing the ionic strength of the diafiltration buffer. It is possible that this also prevented the re-solubilization of other materials, and this may have decreased the pDNA adsorption on the membrane.

\subsubsection{MF-C tests}

A further increase in the ionic strength of the solution was also tested by the addition of $1 \mathrm{M}$ of $\mathrm{CaCl}_{2}$ to the lysates before diafiltration, and the use of diafiltration buffer " $\mathrm{C}$ " (see Section 2.2). The used of $\mathrm{CaCl}_{2}$ aimed, at the same time, to precipitate the RNA present. These tests are labeled MF-C. Addition to the lysates of $1 \mathrm{M}$ of $\mathrm{CaCl}_{2}$ was studied by Eon-Duval et al. [11] that demonstrated the efficacy of this salt on RNA removal, by precipitation. From the application of the model, it was expected that addition of $1 \mathrm{M}$ of $\mathrm{CaCl}_{2}$ to the lysates would not affect the sieving coefficients of the plasmid and RNA species, or their concentration polarization, as it can be seen from the simulations shown in Fig. 3(b) and (d). Only for a pore radius smaller than $10 \mathrm{~nm}$, their sieving coefficients and concentration polarization were expected to be affected, as can be seen in by comparing Figs. 1(a)-4(a) and Figs. 1(b)-4(b), respectively. HIC chromatograms of the lysates before and after $\mathrm{CaCl}_{2}$, shown in Fig. 4(c), indicate that pDNA concentration is not affected by the addition of $\mathrm{CaCl}_{2}$, while showing a very high removal of the hydrophobic compounds, as expected. During the diafiltration process their concentration in the permeates was kept very low, as can be seen from the removal values shown in Fig. 3(f). A 91\% removal of hydrophobic contaminants was obtained by the end of the diafiltration process. The electrophoresis analysis shown in Fig. 4(d) confirms the high removal of RNA obtained by $\mathrm{CaCl}_{2}$ addition, showing that essentially all of the HMw RNA and most of the LMw RNA present in the lysates is removed before diafiltration. The remaining contaminants freely permeate through the microfiltration membrane, as can be seen from the obtained removal values calculated for the filtration step only; these are indicated in Fig. 3(f) with the label "filtration only". Apart from the high removal of RNA obtained by the addition of $\mathrm{CaCl}_{2}$ to the lysates, it was also found that it leads to further precipitation of proteins and especially gDNA before diafiltration (see Table 2). However, a considerably higher pDNA adsorption than in the other tests was also found, near $15 \%$, as suggested by the lower average pDNA yield obtained, compared to the other tests, that was $(84 \pm 1) \%$ for a $(0.3 \pm 0.1) \%$ retention.

\subsection{Ultrafiltration studies}

After the solid/liquid diafiltration operation a second membrane operation was tested to concentrate, and at the same time, purify the plasmid. For this purpose an ultrafiltration membrane was selected, with $100 \mathrm{kDa}$ of molecular weight cut-off in fluoro polymer, FS40PP from DSS/Alfa Laval, which has a pore size of $4.1 \mathrm{~nm}$ [26]. Concentration of the permeates from tests MF-A, MF-B and MF-C was performed at the constant pressure of $1 \mathrm{bar}$ to a volumetric concentration factor of 3.0. These tests will be referred as UF-A, UF-B and UF-C. Considerably higher fluxes were obtained in tests UF-C than in other experiments, which was probably due to previous removal of the hydrophobic contaminants, as can be seen in Fig. 5(a). The highest plasmid recovery yields were obtained, however, in tests UF-A ( $97 \pm 2 \%)$ as shown in Fig.5(b). In tests UF-B and UF-C the obtained yields were $(93 \pm 2 \%)$ and $(89 \pm 3 \%)$, respectively, as can be seen in the same
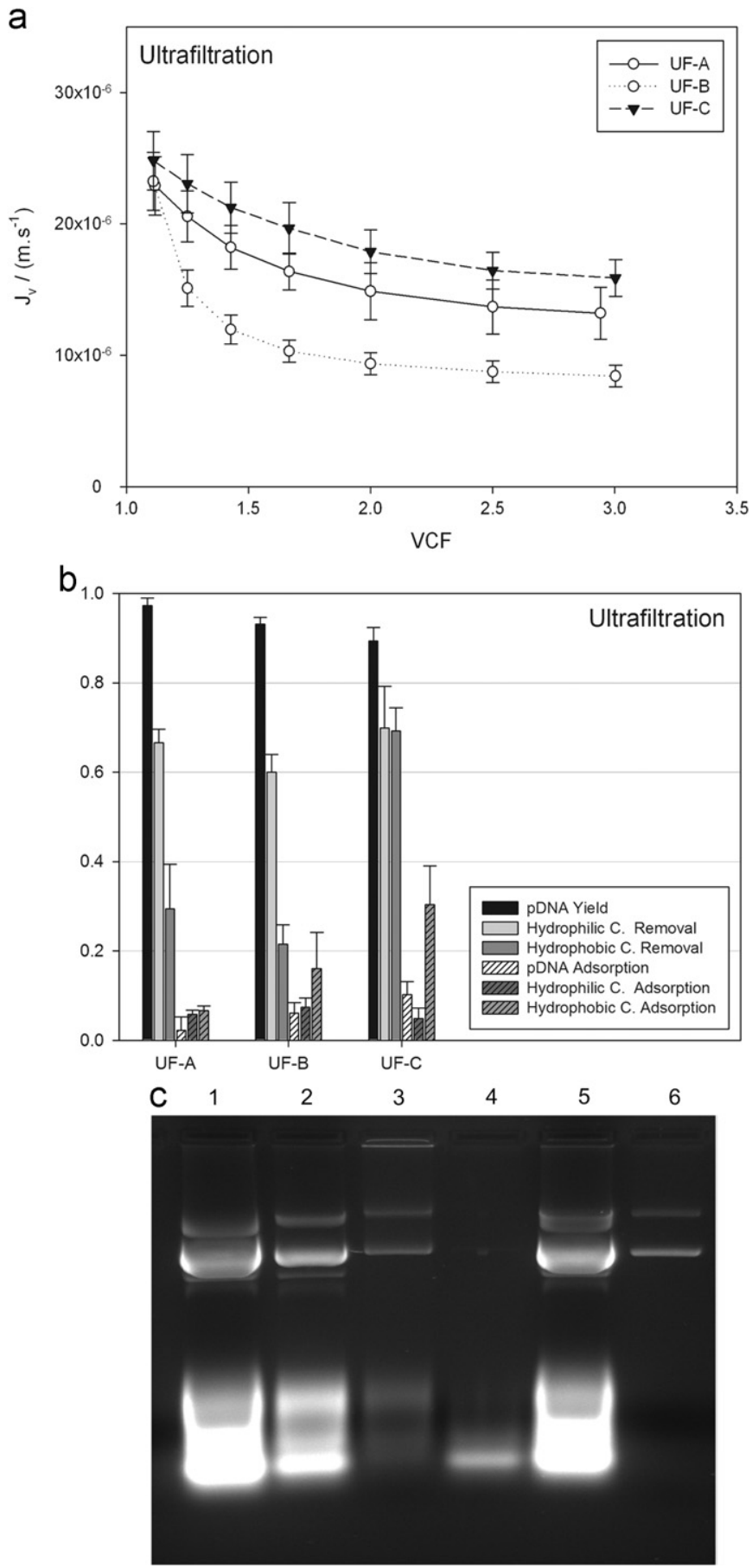

Fig. 5. Results of the concentration operation (ultrafiltration) carried out after diafiltration of the lysates with different buffer solutions. Conditions: $p=1 \mathrm{bar}$ $\omega=760 \mathrm{~min}^{-1}, T=25^{\circ} \mathrm{C}$. (a) Permeation flux as a function of the VCF. (b) Experimental pDNA yields, hydrophilic contaminants removal, hydrophobic contaminants removal and pDNA adsorption. (c) Agarose (1\%) gel electrophoresis analysis during the MF-A/UF-A process. Lanes: (1) lysate; (2) MF permeate; (3) MF retentate; (4) UF permeate; (5) UF concentrate; (6) purified pVAX1-lacZ marker. 
figure. Since in all the permeates the concentration of pDNA was found to be very low, this indicates the occurrence of significant plasmid adsorption in tests UF-B ( $\sim 7 \%)$ and UF-C ( $\sim 11 \%)$; in tests UF-A only $\sim 3 \%$ plasmid adsorption occurred. A very significant permeation of contaminants was found in all the ultrafiltration tests, leading to a significant degree of purification, since the plasmid was always highly retained. In the case of the hydrophilic contaminants it approximately corresponds to the theoretical value for total permeation, which is $66 \%$ for a

a

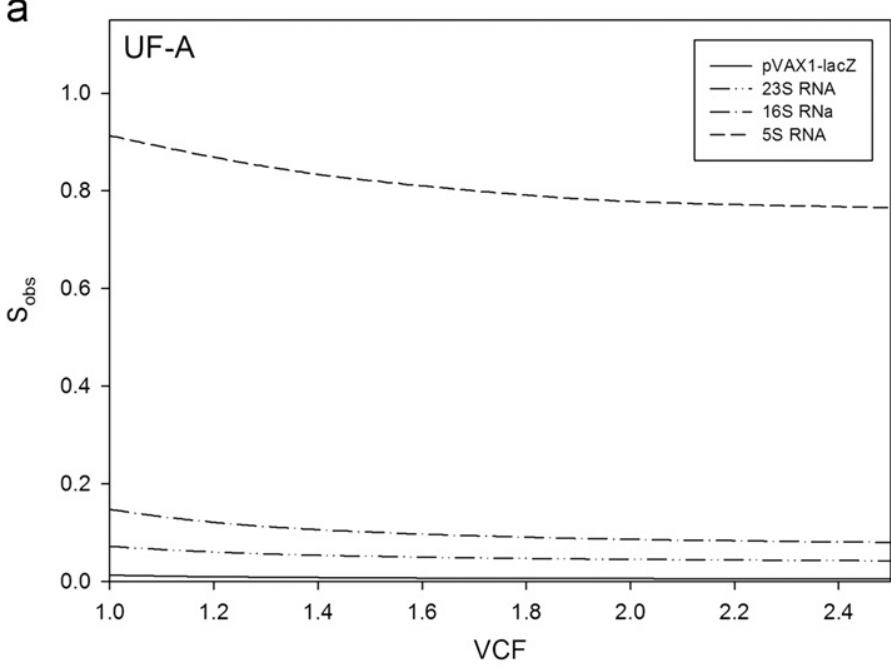

C

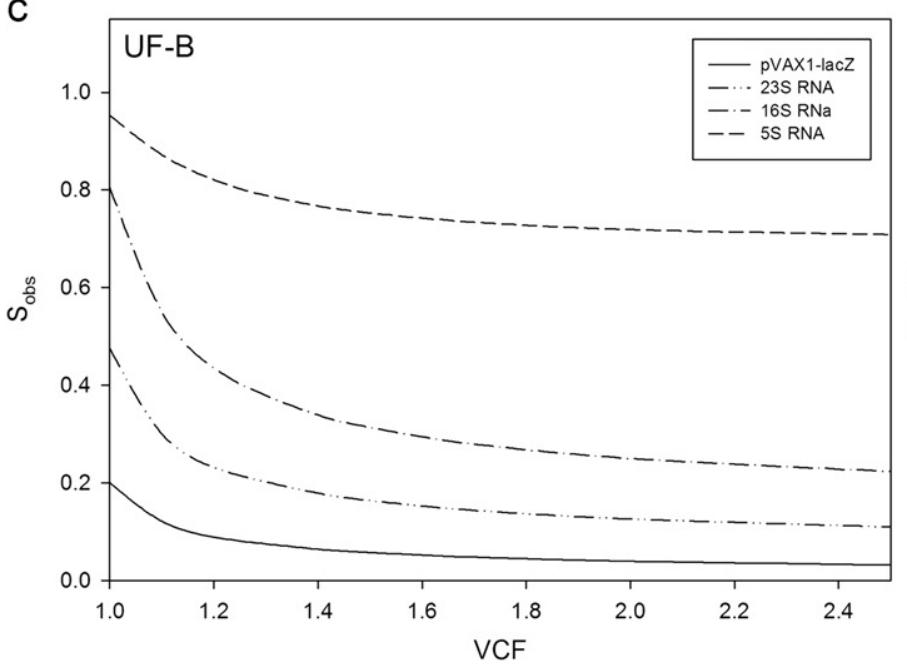

e

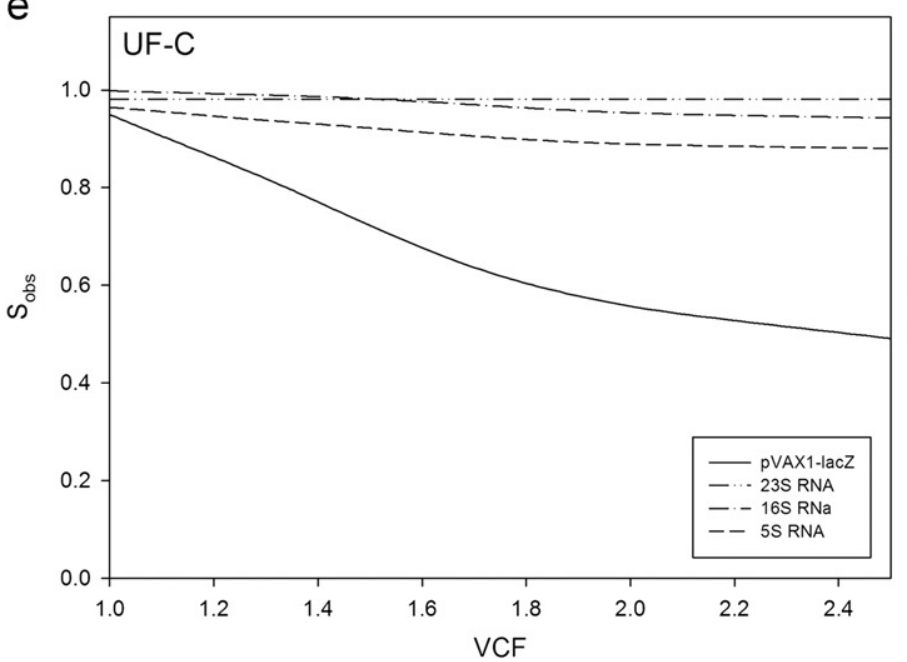

volumetric concentration factor of 3.0. In the case of the hydrophobic contaminants the removal was found to be $20-40 \%$, therefore indicating an average sieving coefficient near 0.5 .

Considering the experimental values of flux, the theoretical sieving coefficients of pDNA and the RNA species can be estimated throughout the different concentration process to interpret the differences found between the plasmid and the contaminants (see Fig. 6). As can be seen in Fig. 6(a) very low $S_{o b s}$ values are
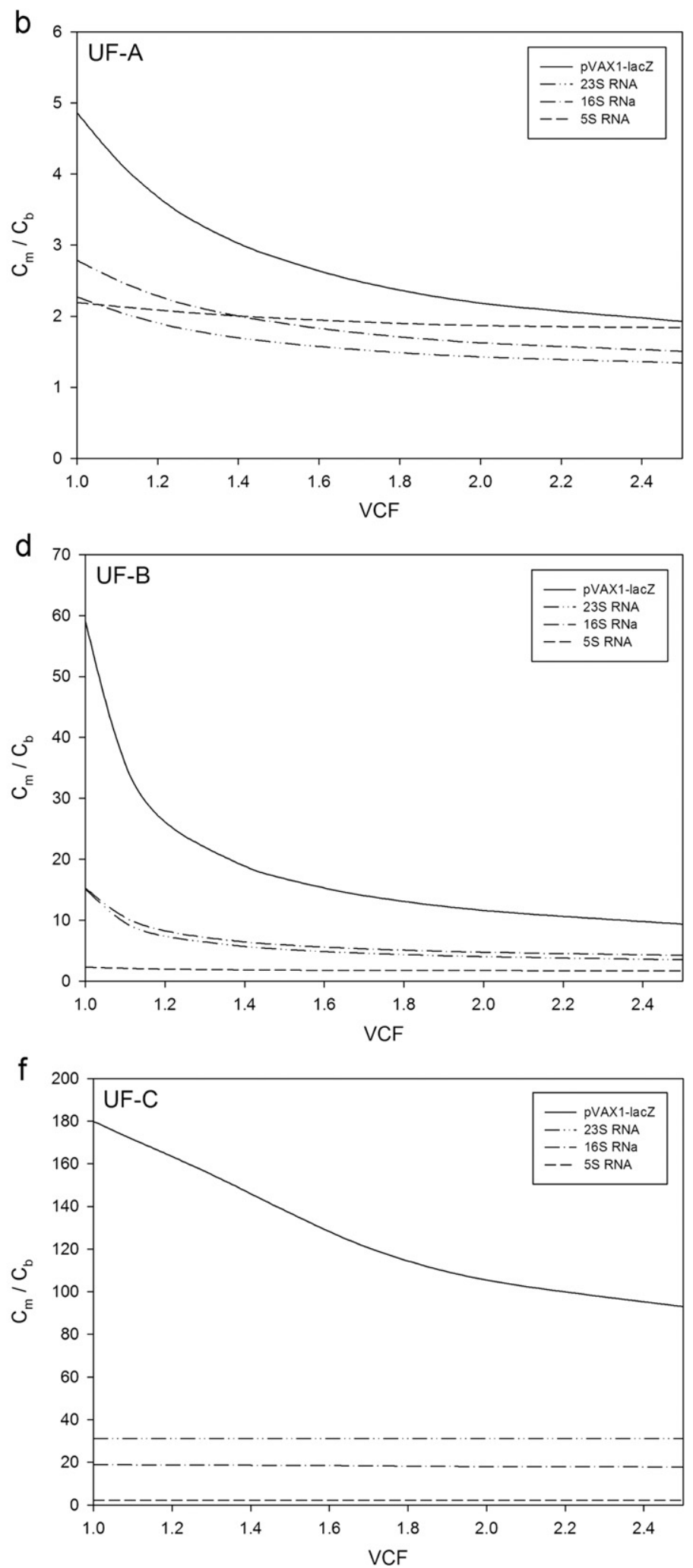

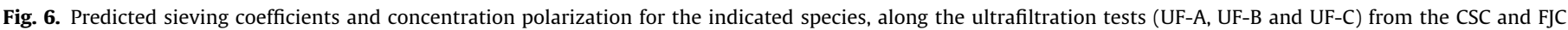
models, considering charge effects, for a membrane with $r_{p}=4.1 \mathrm{~nm}$. Conditions: $J_{v}$ as indicated in Fig. $5, \omega=760 \mathrm{~min}{ }^{-1}, T=25{ }^{\circ} \mathrm{C}$. 
Table 3

Total protein and genomic DNA (gDNA) in the ultrafiltration concentrates (after diafiltration with different buffer solutions), their removal $\left(R_{2}\right)$ in the ultrafiltration operation.

\begin{tabular}{lrllc}
\hline Buffer & Proteins $(\mu \mathrm{g} / \mathrm{ml})$ & $R_{2}(\%)$ & $g D N A(\mu \mathrm{g} / \mathrm{ml})$ & $R_{2}(\%)$ \\
\hline “A” & 64 & 65 & 92 & 28 \\
"B" & 166 & 22 & 44 & 20 \\
“C” & 55 & 59 & 17 & -5 \\
\hline
\end{tabular}

expected for the plasmid along the ultrafiltration process, under the conditions of tests UF-A, a result that agrees with the low permeation experimentally found. As it can be seen in the same figure the model also predicts considerably low $S_{o b s}$ values for both $23 \mathrm{~S}$ and $16 \mathrm{~S}$ RNA, however not for 5S RNA. This probably explains the intermediate values of the average sieving coefficient found for the hydrophobic compounds, previously mentioned. The results from the electrophoretic analysis, shown in Fig. 5(c) confirm this idea. As can be seen also in the same figure, both the supercoiled and the open circular isoforms of pDNA are retained by the ultrafiltration membrane; in fact, as recently shown by Latulippe and Zydney [32] open circular isoforms of pDNA have lower sieving coefficients than the supercoiled.

Concentration polarization was not excessive during tests UF-A, as can be seen from the model simulations in Fig. 6(b), and this probably explains the lower plasmid adsorption found compared to the other ultrafiltration tests. In fact, for the other tests it was theoretically expected that the concentration polarization increased, due to the increase of the ionic strength, as can be seen in Fig. 6(d) and (f). A higher concentration polarization could lead to higher plasmid (and RNA) permeation or to a higher adsorption in tests UF-B and UF-C, compared to tests UF-A. As it can be concluded from the experimental results, shown in Fig. 5(b), it lead to higher adsorption. Therefore, the predicted sieving coefficients in tests UF$B$ and UF-C, shown in Fig. 6(c) and (e) were not accurate due to occurrence of adsorption. The high tendency of pDNA to adsorb in membrane filtration in conditions of high concentration polarization was previously identified in tests performed with model solutions [25]. High permeation of proteins through the ultrafiltration membrane was found, except the case of buffer "B" tests as can be seen in Table 3. From the SEC analysis made in Appendix I, it can be concluded that the proteic material present in the lysates has smaller molecular dimensions than the LMw RNA; accordingly it ought to permeate the ultrafiltration membrane. In the case of buffer "B" tests, protein permeation was probably affected by the membrane fouling, which was higher than in the other tests, as shown in Fig. 6(a).

Significant permeation of gDNA was observed in the case of buffers "A" and " $B$ ", indicating the presence of gDNA fragments of smaller molecular dimensions than the plasmid, which is retained. The highest gDNA removal was found in tests UF-A, followed by UF-B and then UF-C tests; in UF-C tests no gDNA was removed. Thus, when gDNA re-solubilization was higher during the microfiltration step, the removal of gDNA in the ultrafiltration step was also higher (see Tables 2 and 3), a fact that strongly suggests that it is the break-up of the DNA chains that leads to the re-solubilization process of gDNA. From the gDNA removal values obtained in tests UF-A and UF-B (indicated in Table 3 ) the average molecular size of the gDNA fragments that reach the ultrafiltration operation can be estimated as described in Appendix II. If one considers that these fragments are linear double stranded DNA (dsDNA) the number of base pairs of these fragments should be, according to the calculations performed, 205 in the case of buffer " $A$ " and 1700 in the case of buffer "B". These values correspond to the hydrodynamic radii of $16 \mathrm{~nm}$ and $59 \mathrm{~nm}$, respectively, which indicate that these fragments are considerably smaller in size than the plasmid used in this work, for which $r_{s}=83 \mathrm{~nm}$. Therefore, it can be concluded from these results, that although gDNA re-dissolves during microfiltration, the resulting gDNA fragments can be removed in the ultrafiltration operation. A diafiltration can be performed in the second filtration step to achieve higher gDNA removals than those indicated in Table 3, namely when using buffers "A" and "B"; this will be object of study in future work

\section{Conclusions}

The theoretical mass transfer models for CSC and FJC developed to predict pDNA and RNA permeation in the microfiltration of lysates and subsequent membrane concentration were successfully applied, as the results obtained in the two membrane filtration operations can be essentially explained on that theoretical basis.

Recovery of the $6050 \mathrm{bp}$ plasmid selected for this study from lysates was efficiently performed by microfiltration, using a hydrophilic nylon membrane, with $0.2 \mu \mathrm{m}$ of nominal pore size. This pore size and the operating conditions were selected on a theoretical basis to avoid excessive concentration polarization of the plasmid, and its adsorption at the membrane surface as much as possible. It was found that other contaminants namely RNA, proteins and gDNA permeated through the microfiltration membrane together with the plasmid. The addition of $1 \mathrm{M}$ of $\mathrm{CaCl}_{2}$ to the lysates was found to enable an almost complete removal of RNA, as expected from the literature; it was also found that it significantly decreases the amount of gDNA present. The latter tends to re-dissolve during the microfiltration operation, a fact observed in all tests. An increase in the ionic strength of the diafiltration buffer can be used to decrease the re-solubilization of gDNA, but it does not completely avoids it.

Ultrafiltration was studied to purify and concentrate the plasmid after the microfiltration operation. Although high molecular weight RNA is completely retained by the ultrafiltration membrane some permeation of low molecular weight RNA was found, as predicted by the model. Proteins and also gDNA can be significantly removed by ultrafiltration. The high permeability of gDNA fragments in the ultrafiltration operation can be explained by their relatively low molecular size, which was estimated to be considerably smaller than that of the plasmid used in this work. Therefore, although significant re-solubilization of gDNA occurs during the microfiltration step, the fragments that appear in solution are small in size and can be separated from the plasmid in the ultrafiltration step. The best methodology to maximize the purification of the plasmid by ultrafiltration should be studied in future work.

\section{Nomenclature}

bp base pairs (dimensionless)

$C_{b} \quad$ concentration of the solute in the bulk of the solution being filtered $\left(\mathrm{mol} \mathrm{m}^{-3}\right)$

$C_{m} \quad$ concentration of the solute in the solution near the membrane $\left(\mathrm{mol} \mathrm{m}^{-3}\right)$

$C_{p} \quad$ concentration of the solute in the permeate $\left(\mathrm{mol} \mathrm{m}^{-3}\right)$

$D$ diffusion coefficient $\left(\mathrm{m}^{2} \mathrm{~s}^{-1}\right)$

$J_{v} \quad$ volumetric flux though the membrane $\left(\mathrm{m} \mathrm{s}^{-1}\right)$

Mw molecular weight (Da)

$N_{A} \quad$ Avogadro number $\left(\mathrm{mol}^{-1}\right)$

nbp number of base pairs (dimensionless)

$p \quad$ pressure $(\mathrm{Pa})$

$R_{1} \quad$ removal of a certain contaminant in the first filtration step. One minus the ratio of the amount of contaminant in the permeate to the amount in the feeding solution (dimensionless)

$R_{2} \quad$ removal of a certain contaminant in the second filtration step. One minus the ratio of the amount of contaminant in the concentrate to the amount in the feeding solution (dimensionless)

$r_{g} \quad$ average gyration radius ( $\left.\mathrm{m}\right)$

$r_{p} \quad$ pore radius $(\mathrm{m})$

$r_{s} \quad$ average hydrodynamic radius (m)

$s \quad$ sedimentation coefficient (s)

$S_{m} \quad$ intrinsic sieving coefficient (dimensionless)

$S_{\text {obs }} \quad$ observed sieving coefficient (dimensionless)

$T \quad$ absolute temperature (K)

VCF volumetric concentration factor (dimensionless)

$V D F \quad$ volumetric dilution factor (dimensionless)

$v_{s} \quad$ partial specific volume $\left(\mathrm{m}^{3} \mathrm{~kg}^{-1}\right)$ 
Greek symbols

$$
\begin{array}{ll}
\eta & \text { viscosity (Pa s) } \\
\rho & \text { density }\left(\mathrm{kg} \mathrm{m}^{-3}\right) \\
\omega & \text { angular velocity }(\mathrm{rad} / \mathrm{s})
\end{array}
$$

\section{Acknowledgments}

Fundação para a Ciência e a Tecnologia (FCT) for the financial support (PTDC/EBB-BIO/114320/2009) and the grants awarded to António Morão (SFRH/BPD27170/2006) and José Carlos Nunes (SFRH/BD/48801/2008). Financial support from project FCOMPOl-0124-FEDER-014757_FCT PTDC/EBB-BI0/114320/2009 is also gratefully acknowledged.

\section{Appendix I-Brief analytical study of the lysates}

Typical HIC chromatograms of the lysates show three distinct regions, as it can be seen in Fig. A1. The first is a peak with a maximum near $0.7 \mathrm{ml}$ (region 1) which has been attributed in literature to pDNA $[12,27,28]$, that is highly hydrophilic in nature; the second is a group of three peaks with maxima near 1.3, 1.5 and $1.8 \mathrm{ml}$ (region 2) due to hydrophilic contaminants, and the third is a peak with a maximum near $4.5 \mathrm{ml}$ (region 3 ) due to hydrophobic contaminants that are only eluted when the ionic conductivity of the eluent is suddenly decreased. The peaks in region 2 can be essentially attributed to low molecular weight compounds, including most of the proteic material, and also by UV absorption of the buffer species (the base line is not flat); the peak in region 3 is essentially due to RNA, as can be concluded from the size exclusion chromatography (SEC) study described as follows.

Lysate samples were analyzed by SEC using a Sephacryl S-100 $\mathrm{h}$ gel (GE Healthcare) which has a fractionation range of $1-100 \mathrm{kDa}$ for globular proteins [33]. The eluates were collected in fractions, as indicated in Fig. A2(a) that were further analyzed by agarose gel electrophoresis as shown in Fig. A2(b), HIC as shown Fig. A2(c) and total protein content as shown in Fig. A2(a) also. As it can be seen, the high molecular weight nucleic acids (pDNA and HMw RNA) are not retained by the gel used (i.e., are totally excluded) and therefore these species are eluted together in fraction 4. LMw RNA is slightly retained being divided between fractions 4 and 5 .

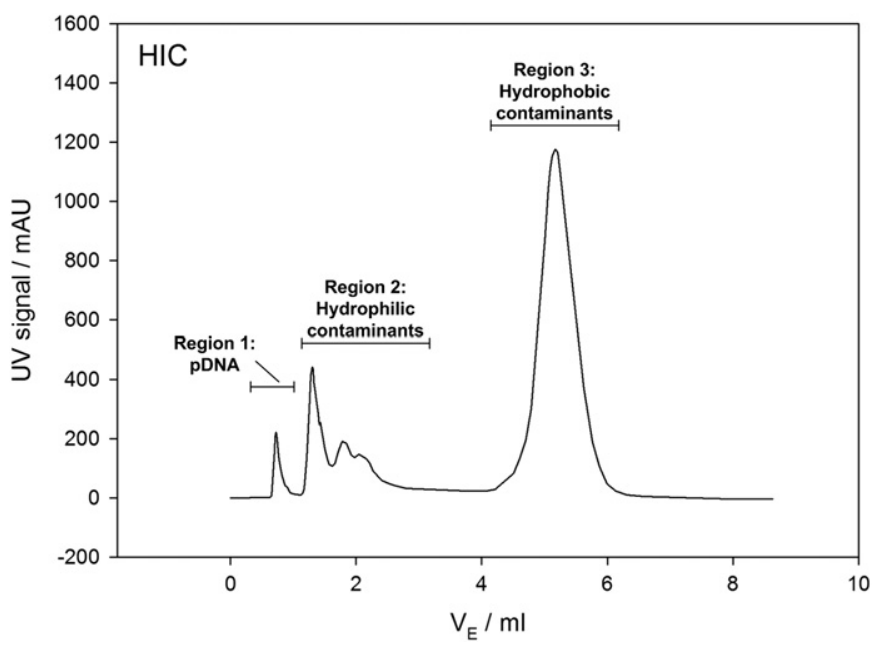

Fig. A1. HIC of a typical lysate. Practical definition of hydrophilic and hydrophilic contaminants used in this work.
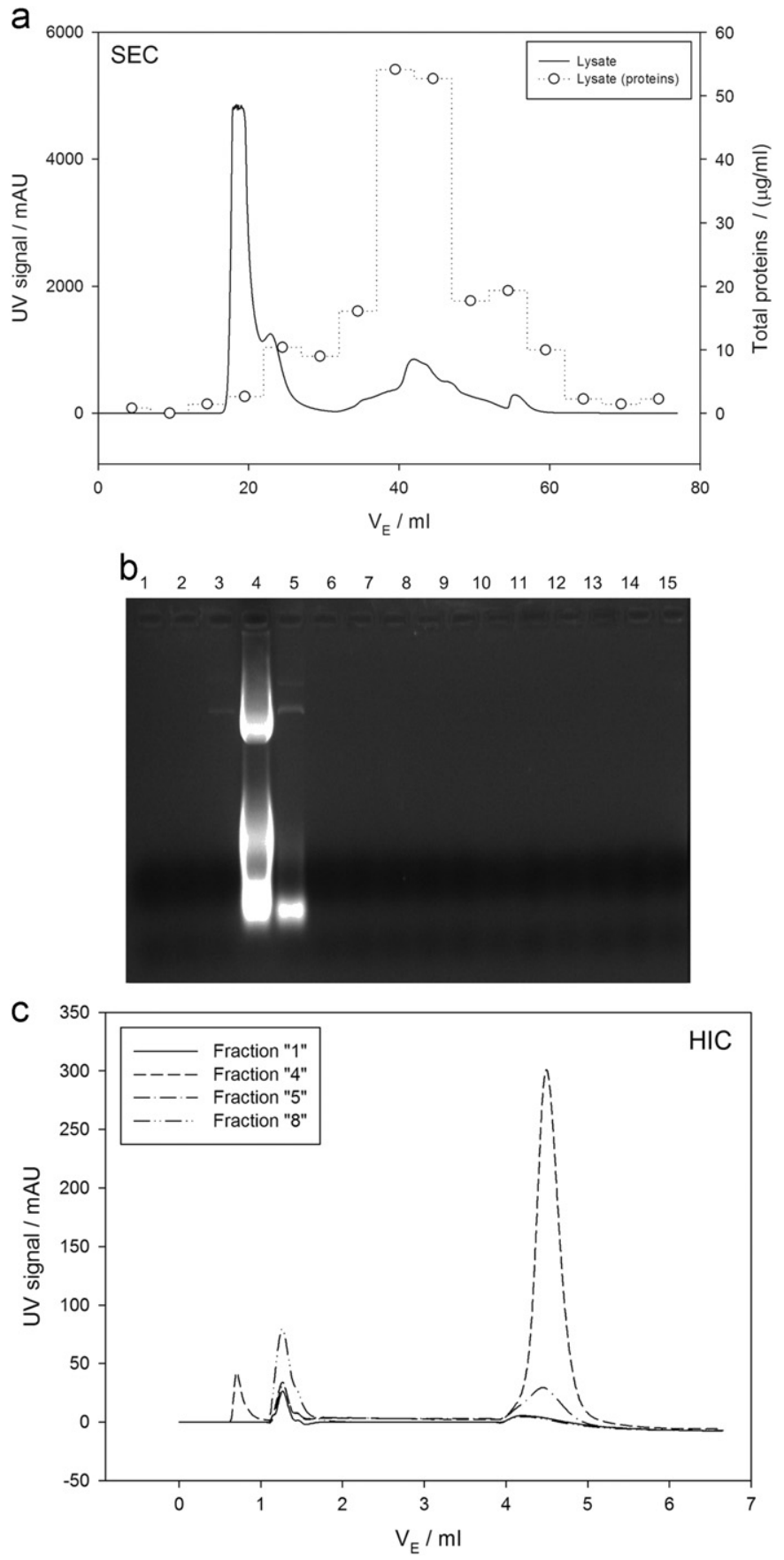

Fig. A2. (a) SEC chromatogram of a typical lysates, in Sephacryl S-100 $h$, with indication of the various fractions collected for further electrophoresis, HIC and total protein analysis. Superimposed to the chromatogram is the total protein content in each fraction. (b) Agarose (1\%) gel electrophoresis analysis of the various fractions from SEC. (c) HIC chromatograms of selected fractions from SEC.

Proteins are significantly retained by the gel, and comprehend a wide range of molecular weight values, considering that they are collected from fractions 5-12, covering almost the entire fractionation range of the gel. As it can be concluded from the HIC chromatograms of the various fractions, all the RNA is eluted in region 3; in fact, it is only for the fractions that contain nucleic acids (i.e., 4 and 5) that absorbance is significant in region 3 and for these fractions no significant absorbance is detected in region 2. Moreover, by comparing the HIC chromatograms of the lysates obtained at $280 \mathrm{~nm}$ to similar chromatograms obtained at $260 \mathrm{~nm}$ (not shown) it was found that the ratio of UV absorption at 
260-280 nm at the peak in "region 3" approaches the value of 2 , which is also indicative that this peak is essentially due to nucleic acids (thus RNA). The proteins with the highest molecular size (that are eluted in fraction 5) may be also hydrophobic and may contribute to the peak in region 3 , not in region 2 , where the other proteins are eluted; however, this should be a small contribution, as it can be inferred from the SEC chromatograms. Therefore, we have clear evidences that most of the hydrophobic contaminants are RNA.

\section{Appendix II-Estimative of the size of gDNA fragments}

Modeling the permeation of gDNA fragments in the ultrafiltration membrane can be carried out by assuming that these fragments are linear double stranded DNA (dsDNA). The average number of base pairs of these fragments can be estimated from permeation data, according to the following procedure. Since the permeate flux and also gDNA concentration vary along the ultrafiltration process, the average sieving coefficient of the gDNA fragments also varies. Thus, it is convenient to divide the concentration process in a certain number discrete steps in which one can assume constant values of permeate flux and sieving coefficient of gDNA. For each discrete step the initial gDNA concentration will be known from the final concentration obtained in the previous step, or in the case of the first step, from the initial concentration of gDNA. From an initial guess of the number of base pairs, the diffusion coefficient of linear dsDNA and the corresponding hydrodynamic radius can be estimated using Eq. (11) and Eq. (12) of [26], respectively, and the gyration radius from $r_{s}$, using Eq. (6) of [26]. The intrinsic sieving coefficient of linear dsDNA can be predicted in membrane filtration using the FJC approach, like in the case of RNA modeling. An approach to the observed sieving coefficient of the plasmid, in each step, can be obtained by considering a 3-component system in which component " 1 " is gDNA, component " 2 " is $\mathrm{CH}_{3} \mathrm{COO}^{-}$ and component " 3 " is $\mathrm{K}^{+}$, similarly as described in Section 2.4. The extended NP equations should be used to describe mass transfer in the concentration polarization layer. The gDNA fragments will have a molecular charge equal to $-(2 \mathrm{nbp})$ since it is dsDNA. In each step, the obtained sieving coefficient can be used to estimate the final concentration of gDNA. In the last step the

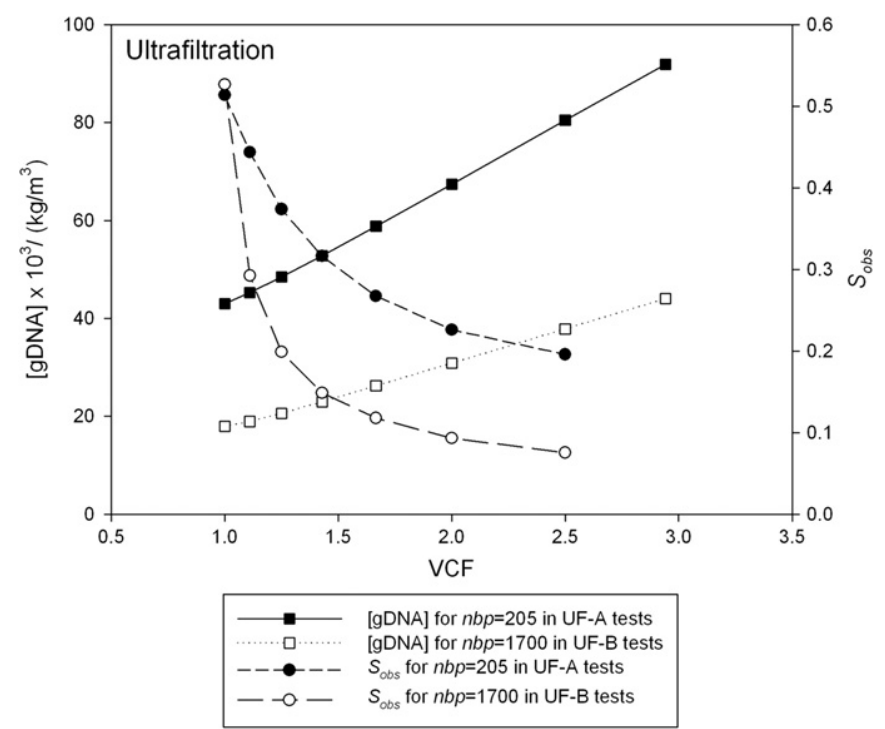

Fig. A3. Estimated values of gDNA concentration in the retentate and average sieving coefficients, as a function of the volumetric concentration factor, in ultrafiltration tests UF-A and UF-B for the optimal values of $n b p$ found. final concentration can be compared to the experimental value of gDNA concentration found for the retentate and the absolute error calculated. Then, a new guess for $n b p$ can be considered, and the process repeated until obtaining a satisfactory approach for $n b p$, for which the error obtained is acceptable.

The best values obtained for the $n b p$ in tests UF-A and UF-B were 205 and 1700 respectively. This does not necessary implies the presence of much smaller fragments in tests UF-A, but probably a higher fraction of small fragments among all the gDNA in solution. The estimated values of gDNA concentration in the retentate along these ultrafiltration experiments calculated using these $n b p$ are shown in Fig. A3, as well as the estimated average sieving coefficients.

\section{References}

[1] 〈http://www.abedia.com/wiley/vectors.php $\rangle$.

[2] Y. Cai, S. Rodriguez, R. Rameswaran, R. Draghia-Akli, R.J. Juba, H. Hebel, Production of pharmaceutical-grade plasmids at high concentration and high supercoiled percentage, Vaccine 28 (2010) 2046-2052.

[3] A. Mountain, Gene therapy: the first decade, Trends Biotechnol. 18 (2000) 119-128.

[4] F. Sousa, L. Passarinha, J.A. Queiroz, Biomedical application of plasmid DNA in gene therapy: a new challenge for chromatography, Biotechnol. Genet. Eng. Rev. 26 (2009) 83-116.

[5] M.A. Liu, DNA vaccines: a review, J. Intern. Med. 253 (2003) 402-410.

[6] M.A. Liu, DNA vaccines: an historical perspective and view to the future, Immunol. Rev. 239 (2011) 62-84.

[7] M.A. Kutzler, D.B. Weiner, DNA vaccines: ready for prime time? Nat. Rev. Genet. 9 (2008) 776-788.

[8] K.J. Prather, S. Sagar, J. Murphy, M. Chartrain, Industrial scale production of plasmid DNA for vaccine and gene therapy: plasmid design, production, and purification, Enzyme Microb. Technol. 33 (2003) 865-883.

[9] F. Sousa, J.A. Queiroz, Supercoiled plasmid quality assessment by analytical arginine-affinity chromatography, J. Chromatogr. A 1218 (2011) 124-129.

[10] F. Smrekar, A. Podgornik, M. Ciringer, S. Kontrec, P. Raspor, A. Strancar, M. Peterka, Preparation of pharmaceutical-grade plasmid DNA using methacrylate monolithic columns, Vaccine 28 (2010) 2039-2045.

[11] A. Eon-Duval, R.H. MacDuff, C.A. Fisher, M.J. Harris, C. Brook, Removal of RNA impurities by tangential flow filtration in an RNase-free plasmid DNA purification process, Anal. Biochem. 316 (2003) 66-73.

[12] F. Sousa, S. Freitas, A.R. Azzoni, D.M.F. Prazeres, J. Queiroz, Selective purification of supercoiled plasmid DNA from clarified cell lysates with a single histidine-agarose chromatography step, Biotechnol. Appl. Biochem. 45 (2006) 131-140.

[13] D.W. Kahn, M.D. Butler, D.L. Cohen, M. Gordon, J.W. Kahn, M.E. Winkler, Purification of plasmid DNA by tangential flow filtration, Biotechnol. Bioeng. 69 (2000) 101-106.

[14] R.J. Lander, M.A. Winters, F.J. Meacle, B.C. Buckland, A.L. Lee, Fractional precipitation of plasmid DNA from lysate by CTA, Biotechnol. Bioeng. 79 (2002) 776-784.

[15] A. Carlson, M. Signs, L. Liermann, R. Boor, K.J. Jem, Mechanical disruption of Escherichia-coli for plasmid recovery, Biotechnol. Bioeng. 48 (1995) 303-315.

[16] D.S. Holmes, M. Quigley, A rapid boiling method for the preparation of bacterial plasmids, Anal. Biochem. 114 (1981) 193-197.

[17] K.C. Zhu, H.L. Jin, Y.J. Ma, Z.H. Ren, C. Xiao, Z.H. He, F.C. Zhang, Q.H. Zhu, B. Wang, A continuous thermal lysis procedure for the large-scale preparation of plasmid DNA, J. Biotechnol. 118 (2005) 257-264.

[18] H.C. Birnboim, J. Doly, Rapid alkaline extraction procedure for screening recombinant plasmid DNA, Nucleic Acids Res. 7 (1979) 1513-1523.

[19] C.S. Chang, H.S. Ni, S.Y. Suen, W.C. Tseng, H.C. Chiu, C.P. Chou, Preparation of inorganic-organic anion-exchange membranes and their application in plasmid DNA and RNA separation, J. Membr. Sci. 311 (2008) 336-348.

[20] I. Theodossiou, I.J. Collins, J.M. Ward, O.R.T. Thomas, P. Dunnill, The processing of a plasmid-based gene from E-coli. Primary recovery by filtration, Bioprocess Eng. 16 (1997) 175-183.

[21] A. Frerix, P. Geilenkirchen, M. Muller, M.R. Kula, J. Hubbuch, Separation of genomic DNA, RNA, and open circular plasmid DNA from supercoiled plasmid DNA by combining denaturation, selective renaturation and aqueous twophase extraction, Biotechnol. Bioeng. 96 (2007) 57-66.

[22] S. Chamsart, H. Patel, J.A.J. Hanak, A.G. Hitchcock, A.W. Nienow, The impact of fluid-dynamic-generated stresses on chDNA and pDNA stability during alkaline cell lysis for gene therapy products, Biotechnol. Bioeng. 75 (2001) 387-392.

[23] M.S. Levy, R.D. O’Kennedy, P Ayazi-Shamlou, P. Dunnill, Biochemical engineering approaches to the challenges of producing pure plasmid DNA, Trends Biotechnol. 18 (2000) 296-305.

[24] D. Kendall, G.J. Lye, M.S. Levy, Purification of plasmid DNA by an integrated operation comprising tangential flow filtration and nitrocellulose adsorption, Biotechnol. Bioeng. 79 (2002) 816-822. 
[25] A.M. Morão, J.C. Nunes, F. Sousa, M.T. Pessoa de Amorim, I.C. Escobar, J.A. Queiroz, Ultrafiltration of supercoiled plasmid DNA: modeling and application, J. Membr. Sci. 378 (2011) 280-289.

[26] A. Morão, J.C. Nunes, F. Sousa, M.T. Pessoa de Amorim, I.C. Escobar, J.A. Queiroz, Development of a model for membrane filtration of long and flexible macromolecules: application to predict dextran and linear DNA rejections in micro and ultrafiltration, J. Membr. Sci. 336 (2009) 61-70.

[27] M.M. Diogo, J.A. Queiroz, D.M.F. Prazeres, Assessment of purity and quantification of plasmid DNA in process solutions using high-performance hydrophobic interaction chromatography, J. Chromatogr. A 998 (2003) 109-117.

[28] A.G. Gomes, A.M. Azevedo, M.R. Aires-Barros, D.M.F. Prazeres, Clearance of host cell impurities from plasmid-containing lysates by boronate adsorption, J. Chromatogr. A 1217 (2010) 2262-2266.
[29] S.A. Martins, D.M. Prazeres, J.M. Cabral, G.A. Monteiro, Comparison of realtime polymerase chain reaction and hybridization assays for the detection of Escherichia coli genomic DNA in process samples and pharmaceutical-grade plasmid DNA products, Anal. Biochem. 322 (2003) 127-129.

[30] S.S. Freitas, J.A.L. Santos, D.M.F. Prazeres, Plasmid purification by hydrophobic interaction chromatography using sodium citrate in the mobile phase, Sep. Purif. Technol. 65 (2009) 95-104.

[31] D. Voet, J. Voet, Biochemistry, 2nd ed., John Wiley \& Sons, 1995.

[32] D.R. Latulippe, A.L. Zydney, Separation of plasmid DNA isoforms by highly converging flow through small membrane pores, J. Colloid Interface Sci. 357 (2011) 548-553.

[33] Amersham Pharmacia Biotech, Gel filtration, 8th ed., 1998. 